\title{
Tying Down the Anchor: Monetary Policy Rules and the Lower Bound on Interest Rates
}

\author{
Thomas M. Mertens \\ Federal Reserve Bank of San Francisco \\ John C. Williams \\ Federal Reserve Bank of New York
}

August 2019

Working Paper 2019-14

https://www.frbsf.org/economic-research/publications/working-papers/2019/14/

\section{Suggested citation:}

Mertens, Thomas M., and John C. Williams. 2019. “Tying Down the Anchor: Monetary Policy Rules and the Lower Bound on Interest Rates,” Federal Reserve Bank of San Francisco Working Paper 2019-14. https://doi.org/10.24148/wp2019-14

The views in this paper are solely the responsibility of the authors and should not be interpreted as reflecting the views of the Federal Reserve Bank of San Francisco or the Board of Governors of the Federal Reserve System. 


\title{
Tying Down the Anchor: Monetary Policy Rules and the Lower Bound on Interest Rates
}

\author{
Thomas M. Mertens and John C. Williams*
}

August 14, 2019

\begin{abstract}
This paper uses a standard New Keynesian model to analyze the effects and implementation of various monetary policy frameworks in the presence of a low natural rate of interest and a lower bound on interest rates. Under a standard inflation-targeting approach, inflation expectations will be anchored at a level below the inflation target, which in turn exacerbates the deleterious effects of the lower bound on the economy. Two key themes emerge from our analysis. First, the central bank can eliminate this problem of a downward bias in inflation expectations by following an average-inflation targeting framework that aims for above-target inflation during periods when policy is unconstrained. Second, dynamic strategies that raise inflation expectations by keeping interest rates "lower for longer" after periods of low inflation can both anchor expectations at the target level and further reduce the effects of the lower bound on the economy.
\end{abstract}

JEL Classification System: E52

\footnotetext{
${ }^{*}$ Mertens: Federal Reserve Bank of San Francisco, 101 Market Street, Mailstop 1130, San Francisco, CA 94105; Thomas.Mertens@sf.frb.org. Williams: Federal Reserve Bank of New York, 33 Liberty Street, New York, NY 10045; John.C.Williams@ny.frb.org. We thank Richard Clarida, Marc Giannoni, Krishna Guha, Monika Piazzesi, John Taylor, and audiences at the Federal Reserve Bank of Dallas, the University of Texas at Austin, and the Hoover Institutions conference on "Strategies for Monetary Policy" for helpful discussions. Patrick Adams and Renuka Diwan provided outstanding research assistance. The views expressed in this paper are those of the authors and do not necessarily reflect the positions of the Federal Reserve Bank of San Francisco, the Federal Reserve Bank of New York, or the Federal Reserve System.
} 


\section{Introduction}

The sizable decline in the natural rate of interest observed in many countries over the past quarter-century implies that central banks are now likely to be constrained by the lower bound on nominal interest rates frequently, interfering with their ability to offset negative shocks to the economy (see, for example, Laubach and Williams (2016) and Holston, Laubach and Williams (2017)). As a result, central banks face the challenge of inflation expectations potentially becoming anchored at too low a level, which further limits the policy space available to react to negative shocks to the economy.

This paper studies the effect of various monetary policy frameworks and associated rules on inflation expectations and macroeconomic outcomes. It uses a standard New Keynesian model augmented with a lower bound on interest rates. An essential part of this setup is the forward-looking nature of economic decision making. Inflation is determined via a Phillips curve by which inflation increases with the output gap and expectations about future inflation. The output gap is linked to the real interest rate relative to the natural rate of interest as well as expectations of future output gaps. Both measures of economic activityinflation and the output gap-are subject to uncertainty stemming from shocks on the demand and supply side. The supply shock enters the Phillips curve while the demand shock hits the investment/savings (IS) curve for the output gap. For analytical tractability, we assume that these shocks are uniformly distributed and i.i.d. over time. ${ }^{1}$

To close the model, a central bank sets the nominal interest rate. It chooses a monetary policy rule consistent with its assumed policy framework that dictates the path for the interest rate in every possible scenario, and evaluates the rule according to its social loss. Importantly, the central bank can credibly communicate its interest rate rule so that expectations about future economic activity can adjust. The social loss function penalizes deviations of the rate of inflation from its target as well as positive or negative output gaps. A parameter for the conservativeness of the central bank controls the relative weight that the central bank assigns to stabilizing output versus inflation. The choice of the policy rate is thereby constrained by a lower bound on interest rates. We focus our attention on the central bank's policy rule for the interest rate and abstract from unconventional monetary policy. As a result, the central bank is unable to stimulate the economy beyond cutting the nominal interest rate down to its lower bound. However, the monetary policy framework can entail future policy responses to current economic conditions and therefore influence activity through the expectations channel, similar to forward guidance.

\footnotetext{
${ }^{1}$ Normally distributed shocks lead to a similar analysis, both qualitative and quantitative (see Mertens and Williams (2018)).
} 
In the absence of a lower bound on interest rates, the central bank would find it desirable to fully offset demand shocks while partially, depending on its conservativeness, accommodating supply shocks. Under an optimal interest rate rule, there is a unique equilibrium in which optimal monetary policy features standard inflation targeting. ${ }^{2}$

When the central bank is constrained by a lower bound on interest rates, negative demand and supply shocks cannot be offset to the desired degree. As a result, optimal policy under discretion will result in occasional encounters with the lower bound that lead to below-target inflation and output gaps when the natural rate of interest is sufficiently low, as in Mertens and Williams (2019). Since the private sector will incorporate these scenarios into their forecasts, expectations of inflation and output gaps will be lower than they would be in the absence of a lower bound. The reduction in expectations, in turn, exacerbates the effects of the lower bound on the economy. ${ }^{3}$

We investigate three classes of monetary policy frameworks and their associated policy rules and compare them with our benchmark case of optimal policy under discretion. In the benchmark, policy can be implemented with an interest rate rule that is linear in the supply and demand shocks. Under this policy, occasional encounters with the lower bound on interest rates lead to suboptimally low inflation expectations when the natural rate of interest is sufficiently low. The shortfall in expectations is due to the central bank's inability to stimulate the economy any further when at the lower bound and the lack of commitment to provide stimulus in periods following the encounter with the lower bound on interest rates. In all three classes of monetary policy frameworks, we give the central bank the ability to commit to an interest rate rule.

The first category is standard inflation-targeting frameworks. Aside from the benchmark framework of optimal monetary policy under discretion, we study dovish policies and the introduction of an upper bound on interest rates in this category. An interest rate rule that limits the responsiveness to demand and supply shocks leads to lower social losses. The reason for improved outcomes is that a smaller response to shocks reduces the chances of hitting the lower bound on interest rates. The resulting benefits do not arise from policy setting in the current period but rather an increase in inflation expectations. However, the benefits come at the cost of larger inflation and output variability.

The second category consists of average-inflation targeting policies. First, we consider changes to the

\footnotetext{
${ }^{2}$ There are multiple interest rate rules that can implement optimal policy.

${ }^{3} \mathrm{~A}$ second equilibrium emerges due to the presence of a lower bound. This "liquidity trap" is characterized by lower expectations of inflation and output. Since lower expectations constrain the economy due to the forward-looking nature of the Phillips and IS curves, the probability of a binding lower bound increases. Resulting shortfalls in the output gap and the rate of inflation relative to target confirm expectations and an equilibrium emerges. For the purposes of this paper, we restrict our analysis to the target equilibrium and pay no attention to the liquidity trap. For an empirical investigation, see Mertens and Williams (2018).
} 
intercept in the interest rate rule. Reducing the intercept in the rule is equivalent to targeting a higher inflation rate each period. This in turn feeds back into periods when the lower bound on interest rates is binding and mitigates its effects on the macroeconomy. As a result, higher inflation during normal times spills over to all periods and lowers overall social losses. Average-inflation targeting practices thereby fare better in terms of social losses than dovish policies. However, the central bank can do even better by further raising expected inflation. Additional benefits from inflation expectations above target arise due to the asymmetry of the inflation distribution. This distribution is negatively skewed because of the low inflation scenarios associated with the lower bound. We further show that it is sufficient for the central bank to adjust the intercept of the rule relative to optimal monetary policy under discretion.

As an alternative to this rule, we study an interest rate rule that makes up for past missed stimulus due to the lower bound. Therefore, we allow the central bank to condition its interest rate, in addition to the previous components, on the sum of past shortfalls in interest rate cuts as in Reifschneider and Williams (2000). This dynamic rule leads the rate of inflation to be at target on average. However, due to its conditioning on past shortfalls in interest rate cuts, inflation expectations vary with the shortfall in stimulus and thus fluctuate over time. In particular, since the policy framework calls for more stimulus following episodes of binding lower bounds, i.e. a "lower-for-longer policy," inflation expectations are already higher during a time when the central bank is constrained. As a result, inflation does not drop as far below target and the social loss is lower compared with when only the intercept gets adjusted.

The third class of policies are price-level targeting policies along with their variants. We consider pricelevel targeting within the framework of an interest rate rule that, compared with the rule under discretion, can additionally condition on a price level. Price-level targeting, just like the Reifscheider-Williams rule, leads inflation expectations to adjust dynamically with higher inflation expectations during economic downturns.

We contrast price-level targeting with temporary price-level targeting as proposed by Evans (2010) and Bernanke (2017). For temporary price-level targeting, the price-level target enters the interest rate rule only following an encounter with the lower bound. As soon as the shortfall in inflation has been made up and the price level is back at target, the interest rate rule reverts to the static version. This framework has the advantage that it aims only to change inflation expectations when it is needed and works like standard inflation targeting otherwise.

A key conclusion from our analysis is that all of these policies work through affecting expectations. The monetary policy framework is only in effect during times when the central bank can set interest rates 
freely without being constrained by the lower bound. However, expectations of future policy already affect economic activity during encounters with the lower bound through the forward-looking nature of price setting and decision making.

A comparison among the frameworks shows that there is a ranking among the various policy options. Average-inflation targeting practices fare better than dovish policies. And dynamic policies can improve on adjustments to the level of interest rates. Price-level targeting is known to get close to the first-best policyeven in the absence of a lower bound on interest rates. Particularly, in the presence of supply shocks, this policy framework works best among the alternatives. The Reifschneider-Williams rule has the advantage of addressing the shortfalls in stimulus through cuts in the interest rate directly and works about as well as price-level targeting when demand shocks are the driving factor behind economic fluctuations.

There are three strands of related literature. For each of those, we are able to cite only a few seminal papers due to space constraints. First, there is a literature on the model we use in this paper to perform the policy experiments. The basic framework is laid out in Clarida, Gali and Gertler (1999) and Woodford (2003). Benhabib, Schmitt-Grohé and Uribe (2001) demonstrate how the introduction of a lower bound can lead to two equilibria in a deterministic framework. Mendes (2011), Nakata and Schmidt (2016), and Mertens and Williams (2018) extend this analysis to stochastic environments.

Second, there is a literature on proposals for various policy frameworks. Bernanke and Mishkin (1997) discuss inflation-targeting practices by central banks. Svensson (1999) compares inflation targeting with price-level targeting practices. Giannoni (2014) points out that price-level targeting can be robustly optimal and shows that price-level targeting rules support determinacy of equilibria. Nominal GDP targeting, another proposal that we do not analyze here, is discussed in Taylor (1985) and Koenig (2013). While these policy proposals were discussed mainly without regard to the lower bound on interest rates, there have been several proposals specifically designed to deal with issues arising from a binding constraint on the central bank's actions.

A third strand of the literature compares the various policy options. This paper extends the work in Mertens and Williams (2019) to additional policy options and contains an analysis of a framework with demand shocks. An overview over various policy options can also be found in Svensson (2019). Harrison, Seneca and Waldron (2019) study policy options when interest rates are low. Vestin (2006) shows that pricelevel targeting outperforms inflation targeting in a New Keynesian model without a lower bound on interest rates. Eggertsson and Woodford (2003) compute optimal monetary policy in the presence of a lower bound 
on interest rates. While our paper mainly focuses on the mechanism, Bernanke, Kiley and Roberts (2019) compare the policy options within an estimated model for the U.S. economy.

\section{Macroeconomic Model}

We use a standard New Keynesian model as, for example, described in Clarida, Gali and Gertler (1999) and Woodford (2003) and modify it by incorporating a lower bound. Our focus is primarily on longerterm outcomes, and we thus abstract from some of the transition dynamics that would take place in richer models. Our simple model allows us to derive the mechanisms by which various policy frameworks and their associated interest rate rules affect the economy and evaluate them according to a social loss function.

The model describes the evolution of three endogenous variables: the rate of inflation $\pi_{t}$, the output gap $x_{t}$, and the short-term nominal interest rate $i_{t}$ that is chosen by the central bank. Our starting point is the log-linearized version of the standard New Keynesian model that we simplify by assuming that shocks are i.i.d. This simplification allows us to derive analytical results and focus on the longer-term implications without having to track transition dynamics.

Inflation is governed by the forward-looking Phillips curve

$$
\pi_{t}=\mu_{t}+\kappa x_{t}+\beta \mathbb{E}_{t} \pi_{t+1}, \quad \mu_{t} \sim \operatorname{iidU}[-\hat{\mu}, \hat{\mu}]
$$

where $\mathbb{E}_{t}$ is the expectations operator conditional on time $t$ information, $\mu_{t}$ a supply shock, $\beta \in(0,1)$ the agents' discount factor, and $\kappa>0$. An IS curve, obtained by log-linearizing an Euler equation, determines the output gap

$$
x_{t}=\epsilon_{t}-\alpha\left(i_{t}-\mathbb{E}_{t} \pi_{t+1}-r^{*}\right)+\mathbb{E}_{t} x_{t+1}, \quad \epsilon_{t} \sim \operatorname{iidU}[-\hat{\epsilon}, \hat{\epsilon}],
$$

where $\alpha>0, r^{*}$ is the long-run neutral real rate of interest, and $\epsilon_{t}$ is a demand shock. Agents fully understand the model, including the distribution of the shock processes, and have full knowledge of all realized shocks up to the current period. For better exposition, we study the models with demand and supply shocks separately. To this end, we set the size of the support for the shocks that we want to disregard to zero.

The central bank chooses the short-term nominal interest rate $i_{t}$ and has the ability to commit to a framework described by a policy rule. The choice of policy, however, is constrained by a lower bound on nominal interest rates, $i^{\mathrm{LB}}<r^{*}$. It evaluates its policy framework according to a social loss function that 
favors inflation rates close to a target, normalized to zero, and output close to its potential: ${ }^{4}$

$$
\begin{aligned}
\mathscr{L} & =(1-\beta) \mathbb{E}_{0}\left[\sum_{t=0}^{\infty} \beta^{t}\left(\pi_{t}^{2}+\lambda x_{t}^{2}\right)\right] \\
& =(1-\beta) \sum_{t=0}^{\infty} \beta^{t}\left(\mathbb{E}_{0}\left[\pi_{t}\right]^{2}+\operatorname{Var}_{0}\left[\pi_{t}\right]+\lambda\left(\mathbb{E}_{0}\left[x_{t}\right]^{2}+\operatorname{Var}_{0}\left[x_{t}\right]\right)\right) .
\end{aligned}
$$

The second part of the equation shows that the loss function is determined by the first two moments of inflation and the output gap. It is increasing in the variances and the average deviations of inflation or output from their desired levels.

The parameter $\lambda \geq 0$ specifies the central banker's preferences. For $\lambda=0$, the central bank solely cares about stabilizing inflation, while larger values of $\lambda$ introduce a preference for stabilizing the real side of the economy.

\section{Inflation-targeting frameworks}

In this section, we study various static monetary policy frameworks. We first solve for optimal monetary policy under discretion, which serves as a benchmark policy rule. From there, we start by exploring the benefits of an upper bound on interest rates and dovish policies.

\subsection{Benchmark: Optimal monetary policy under discretion}

In the absence of a lower bound on nominal interest rates, the central bank can achieve optimal monetary policy under discretion by setting its interest rate depending on the current state of the economy, that can be fully described by the realization of the supply and demand shock as well as expectations about future inflation

$$
i_{t}^{\mathrm{opt}}=\theta_{0}+\theta_{E} \mathbb{E}_{t} \pi_{t+1}+\theta_{\epsilon} \epsilon_{t}+\theta_{\mu} \mu_{t}
$$

where the intercept of the policy rule is $\theta_{0}=r^{*}$, the coefficient on expectations is $\theta_{E}=1+\frac{1}{\alpha \kappa}-\frac{\lambda \beta}{\alpha \kappa\left(\kappa^{2}+\lambda\right)}$, and the responses to demand and supply shocks are $\theta_{\epsilon}=\frac{1}{\alpha}$ and $\theta_{\mu}=\frac{\kappa}{\alpha\left(\kappa^{2}+\lambda\right)}$, respectively.

The interest rate rule in equation (4) can be implemented with a Taylor rule (see Taylor (1993)) of the form

$$
i_{t}^{\mathrm{opt}}=\phi_{0}+\phi_{E} \mathbb{E}_{t} \pi_{t+1}+\phi_{\pi} \pi_{t}+\phi_{x} x_{t}
$$

\footnotetext{
${ }^{4}$ It is straightforward to generalize to a nonzero inflation target by interpreting $\pi_{t}$ as the gap between inflation and its target.
} 
Setting the coefficients to $\phi_{0}=r^{*}, \phi_{E}=\frac{\kappa\left(-\alpha \theta_{\epsilon}-\beta \theta_{\mu}+\theta_{E}\right)+(1-\beta) \theta_{\epsilon}}{\kappa\left(1-\alpha \theta_{\epsilon}\right)}, \phi_{\pi}=\frac{\theta_{\mu}}{1-\alpha \theta_{\epsilon}}$, and $\phi_{x}=\frac{\theta_{\epsilon}-\kappa \theta_{\mu}}{1-\alpha \theta_{\epsilon}}$ implements the interest rate rule in equation (4). ${ }^{5}$

Under this policy, the inflation process is given by

$$
\pi_{t}=\alpha \kappa\left(r^{*}-\theta_{0}\right)+\left(1-\alpha \kappa \theta_{\mu}\right) \mu_{t}+\kappa\left(1-\alpha \theta_{\epsilon}\right) \epsilon_{t}+\left(1+\alpha \kappa-\alpha \kappa \theta_{E}\right) \mathbb{E}_{t}\left[\pi_{t+1}\right] .
$$

The central bank thus finds it optimal to partially accommodate supply shocks unless its objective is purely to stabilize inflation, i.e., $\lambda=0$. Taking expectations at time $t-1$ on both sides of equation (6) shows that there is a unique steady-state level of expectations $\mathbb{E}_{t-1} \pi_{t}=\mathbb{E} \pi=0$.

When incorporating a lower bound on interest rates, the policy rule that can implement optimal monetary policy under discretion is given by the optimal policy under discretion described above with the addition of the lower bound constraint

$$
i_{t}=\max \left\{\theta_{0}+\theta_{E} \mathbb{E}_{t} \pi_{t+1}+\theta_{\epsilon} \epsilon_{t}+\theta_{\mu} \mu_{t}, i^{L B}\right\}
$$

with the same values for the coefficients as in the unconstrained case of equation (4). Equation (7) can again be written in Taylor-rule from $i_{t}=\max \left\{\phi_{0}+\phi_{E} \mathbb{E}_{t} \pi_{t+1}+\phi_{\pi} \pi_{t}+\phi_{x} x_{t}, i^{L B}\right\}$. While all the rules for the different policies discussed below can be expressed in either form, we present them in terms of the underlying shocks.

Under discretion, the lower bound on interest rate affects the interest rate rule only via inflation expectations when unconstrained and truncates the interest rate distribution on the downside. ${ }^{6}$ As a result, the inflation process follows the same process as in equation (6) whenever the central bank is unconstrained in its policy action. At the constraint, however, the central bank sets an interest rate of $i^{\mathrm{LB}}$, leading to an overall inflation process of

$$
\pi_{t}= \begin{cases}\alpha \kappa\left(r^{*}-i^{\mathrm{LB}}\right)+\mu_{t}+\kappa \epsilon_{t}+(1+\alpha \kappa) \mathbb{E}_{t}\left[\pi_{t+1}\right] & \text { constrained } \\ \alpha \kappa\left(r^{*}-\theta_{0}\right)+\left(1-\alpha \kappa \theta_{\mu}\right) \mu_{t}+\kappa\left(1-\alpha \theta_{\epsilon}\right) \epsilon_{t}+\left(1+\alpha \kappa-\alpha \kappa \theta_{E}\right) \mathbb{E}_{t}\left[\pi_{t+1}\right] & \text { otherwise. }\end{cases}
$$

The central bank is thereby constrained whenever $\theta_{\mu} \mu_{t}+\theta_{\epsilon} \epsilon_{t} \leq i^{L B}-r^{*}-\psi \mathbb{E}_{t} \pi_{t+1}$ where $\psi \equiv\left(1+\frac{1}{\alpha \kappa}-\theta_{E}\right)$. With a sufficiently large support for the supply and demand shocks, the central bank finds itself either constrained in response to negative shocks or unconstrained after positive shocks. The lower bound will

\footnotetext{
${ }^{5}$ To implement the interest rate rule with demand shocks, the coefficients on the output gap and inflation have to be infinite. This result can be seen by plugging the optimal coefficients for the interest rate rule in equation (4) into the coefficients for equation (5).

${ }^{6}$ The optimality of this interest rate rule is derived in detail in Mertens and Williams (2018).
} 
thus be binding occasionally. As a result, expected inflation can be computed from the process of inflation in (8) where we need to take the switching between equations into account depending on whether the lower bound is binding or not

$$
\mathbb{E} \pi=\operatorname{Prob}\left(i_{t}^{\mathrm{opt}}<i^{L B}\right) \mathbb{E}\left[\pi_{t}^{c} \mid i_{t}^{\mathrm{opt}}<i^{L B}\right]+\operatorname{Prob}\left(i_{t}^{\mathrm{opt}} \geq i^{L B}\right) \mathbb{E}\left[\pi_{t}^{u} \mid i_{t}^{\mathrm{opt}} \geq i^{L B}\right]
$$

To illustrate the effects on the probability of a binding lower bound and inflation expectations, we turn to the model that only features supply shocks. There is a cutoff value for the supply shock $\bar{\mu}=$ $\frac{1}{\theta_{\mu}}\left(i^{L B}-\theta_{0}-\theta_{E} \mathbb{E} \pi_{t+1}\right)$ such that interest rates are constrained by the lower bound whenever $\mu_{t}<\bar{\mu}$. Consequently, the constraint can either be always, never, or occasionally binding

$$
\operatorname{Prob}\left(i_{t}^{\text {opt }}<i^{L B}\right)= \begin{cases}1 & \text { if }-\bar{\mu} \leq-\hat{\mu} \\ \frac{1}{2 \hat{\mu}}(\hat{\mu}+\bar{\mu}) & \text { if }-\hat{\mu}<-\bar{\mu}<\hat{\mu} \\ 0 & \text { if }-\bar{\mu} \geq \hat{\mu} .\end{cases}
$$

As a result, inflation expectations are determined by

$$
\mathbb{E} \pi_{t}= \begin{cases}-\alpha \kappa\left(i^{L B}-r^{*}\right)+(1+\alpha \kappa) \mathbb{E} \pi_{t+1} & \text { if }-\bar{\mu} \leq-\hat{\mu} \\ -\frac{\alpha \kappa}{4 \hat{\mu}} \theta_{\mu}(\bar{\mu}+\hat{\mu})^{2}+\left(1+\alpha \kappa\left(1-\theta_{E}\right)\right) \mathbb{E} \pi_{t+1}-\alpha \kappa\left(\theta_{0}-r^{*}\right) & \text { if }-\hat{\mu}<-\bar{\mu}<\hat{\mu} \\ -\alpha \kappa\left(\theta_{0}-r^{*}\right)+(1+\alpha \kappa) \mathbb{E} \pi_{t+1} & \text { if }-\bar{\mu} \geq \hat{\mu} .\end{cases}
$$

This expression shows that expected inflation in the current period is a piecewise quadratic function of expected inflation in the following period, as can be seen in Figure 1. As a result, we can solve this equation for a steady state.

The lower bound on interest rates gives rise to a multiplicity of equilibria, as is known from Benhabib, Schmitt-Grohé and Uribe (2001) for a deterministic economy and Mendes (2011), Nakata and Schmidt (2016), and Mertens and Williams (2018) for a stochastic economy. In particular, there are two levels of expected inflation consistent with a steady state. Relatively benign expectations about inflation in the following period provide stimulus to the economy such that the central bank finds itself unconstrained most of the time. The resulting inflation stabilization confirms the benign expectations we started out with. We refer to this scenario as the "target equilibrium." However if, on the other hand, expected future inflation is low, the central bank 


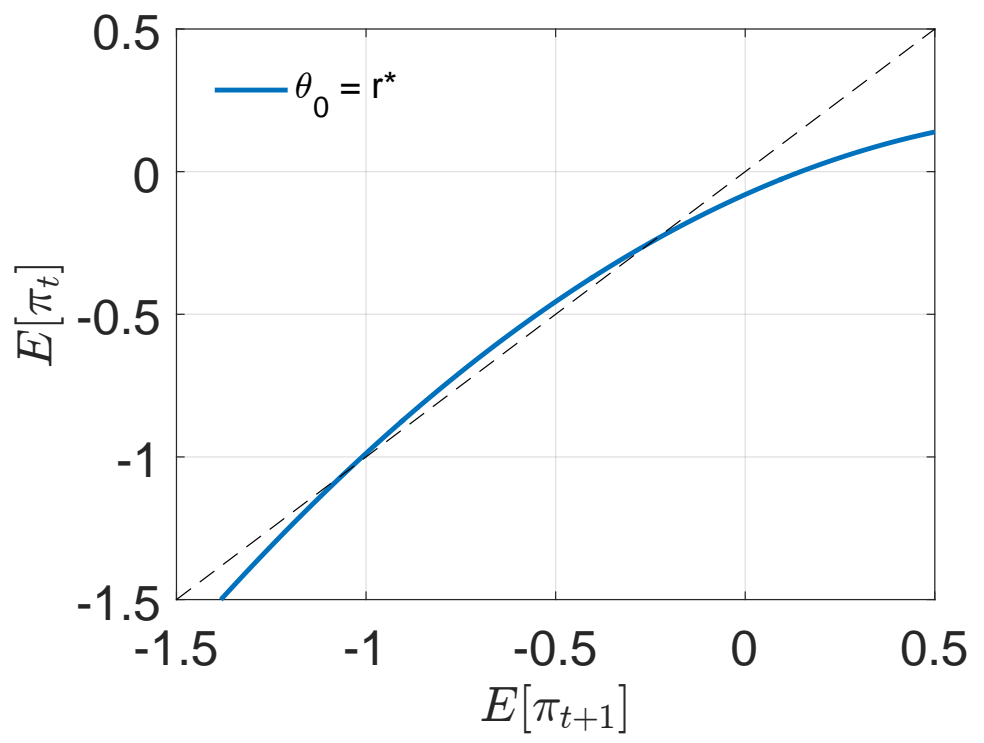

Figure 1: Expected inflation in the current period as a function of expected inflation in the following period. Parameter values are set to $\alpha=1.25, \kappa=0.8, \beta=0.99, r^{*}=1, \lambda=0.25$, and $i^{L B}=-0.5$. The support for supply shocks is $\hat{\mu}=3.3$ and there are no demand shocks, i.e., $\hat{\epsilon}=0$. Intersections with the dashed 45 -degree line represent steady states. The coefficients in the policy rule are those of optimal monetary policy under discretion.

needs to provide more stimulus and reaches the lower bound on interest rates more frequently. Constrained policy results in below-target inflation and thus confirms expectations. The economy is in a "liquidity trap." Throughout the paper, we assume that the economy is in the target equilibrium. ${ }^{7}$

As can be seen from Figure 1, expected inflation runs below the target inflation rate. This shortfall in average inflation is due to inflation expectations taking into account scenarios both with and without binding lower bounds, as shown by equation (9). While interest policy can offset demand and supply shocks to an optimal degree when unconstrained, a binding lower bound leads to below-target inflation. Taking all scenarios into consideration, average inflation and thus inflation expectations are below target. Due to the inability of the central bank to commit to future policy actions under this framework, average inflation runs at a level that is too low relative to the optimum. In the next sections, we show various policy frameworks that can bring about improvements relative to optimal monetary policy under discretion when the central bank can commit to an interest rate rule.

${ }^{7}$ For an empirical investigation lending support to the U.S. economy being in the target equilibrium, see Mertens and Williams (2018). 


\subsection{Static: An upper bound on interest rates}

Since the root of undesirably low inflation expectations lies in the lower bound on interest rates, an upper bound on interest rates might help in anchoring inflation expectations at target. We therefore consider a modification to the interest rate policy under discretion in equation (7) that imposes an upper bound ${ }^{\mathrm{UB}}$

$$
i_{t}=\min \left\{\max \left\{\theta_{0}+\theta_{E} \mathbb{E}_{t} \pi_{t+1}+\theta_{\epsilon} \epsilon_{t}+\theta_{\mu} \mu_{t}, i^{L B}\right\}, i^{\mathrm{UB}}\right\}
$$

To compute inflation expectations, we now have to distinguish between six, instead of three, cases. Both the upper bound and the lower bound can either be always binding ("constrained"), never binding ("unconstrained"), or occasionally binding. We refer to these scenarios as $\mathbb{C}_{u}^{\mathrm{UB}}$ for the upper bound to be never binding, $\mathbb{C}_{c}^{\mathrm{UB}}$ for it to be always binding, and $\mathbb{C}_{0}^{\mathrm{UB}}$ for an occasionally binding upper bound. The lower bound constraints are labeled analogously (see Appendix A for the definitions of when the constraints are binding).

The derivation of inflation expectations for the case where both a lower and upper bound are present and only supply shocks hit the economy works analogously to the case of optimal monetary policy under discretion. Due to the additional constraint, however, the list of distinct cases increases. With various conditions $\mathbb{C}^{\mathrm{LB}}$ and $\mathbb{C}^{\mathrm{UB}}$ on the lower and upper bounds, respectively, we distinguish the cases:

$$
\mathbb{E}\left[\pi_{t}\right]=\left\{\begin{array}{cc}
(1+\alpha \kappa) \mathbb{E}\left[\pi_{t+1}\right]-\alpha \kappa\left(i^{\mathrm{LB}}-r^{*}\right) & \text { if } \mathbb{C}_{c}^{\mathrm{LB}} \\
\left.\frac{\alpha \kappa}{4 \theta_{\mu} \hat{\mu}}\left(i^{\mathrm{UB}}+i^{\mathrm{LB}}-2 \theta_{0}-2 \theta_{E} \mathbb{E}\left[\pi_{t+1}\right]\right)\left({ }^{\mathrm{UB}}-i^{\mathrm{LB}}\right)-2 \theta_{\mu} \hat{\mu}\right)+ & \\
+\left(1+\alpha \kappa\left(1-\theta_{E}\right)\right) \mathbb{E}\left[\pi_{t+1}\right]+\alpha \kappa\left(r^{*}-\theta_{0}\right) & \text { if } \mathbb{C}_{o}^{\mathrm{LB}} \text { and } \mathbb{C}_{o}^{\mathrm{UB}} \\
-\frac{\alpha \kappa \theta_{\mu}}{4 \hat{\mu}}\left(\hat{\mu}+\frac{1}{\theta_{\mu}}\left(i^{\mathrm{LB}}-\theta_{0}-\theta_{E} \mathbb{E}\left[\pi_{t+1}\right]\right)\right)^{2}+ & \\
\left.(1+\alpha \kappa) \mathbb{E}\left[\pi_{t+1}\right]-\alpha \kappa\left(i-i_{E}\right)\right) \mathbb{E}\left[\pi_{t+1}\right]+\alpha \kappa\left(r^{*}-\theta_{0}\right) & \text { if } \mathbb{C}_{o}^{\mathrm{LB}} \text { and } \mathbb{C}_{u}^{\mathrm{UB}} \\
\frac{\alpha \kappa \theta_{\mu}}{4 \hat{\mu}}\left(\hat{\mu}-\frac{1}{\theta_{\mu}}\left({ }_{i}^{\mathrm{UB}}-\theta_{0}-\theta_{E} \mathbb{E}\left[\pi_{t+1}\right]\right)\right)^{2}+ & \text { if } \mathbb{C}_{c}^{\mathrm{UB}} \\
+\left(1+\alpha \kappa\left(1-\theta_{E}\right)\right) \mathbb{E}\left[\pi_{t+1}\right]+\alpha \kappa\left(r^{*}-\theta_{0}\right) & \text { if } \mathbb{C}_{u}^{\mathrm{LB}} \text { and } \mathbb{C}_{o}^{\mathrm{UB}} \\
\left(1+\alpha \kappa\left(1-\theta_{E}\right)\right) \mathbb{E}\left[\pi_{t+1}\right]+\alpha \kappa\left(r^{*}-\theta_{0}\right) & \text { if } \mathbb{C}_{u}^{\mathrm{LB}} \text { and } \mathbb{C}_{u}^{\mathrm{UB}}
\end{array}\right.
$$


As a result of the various conditions, a third equilibrium besides the target equilibrium and the liquidity trap emerges. This equilibrium is associated with the upper bound on nominal interest rates. That is, in the deterministic version of the model, the economy would face a binding upper bound on interest rates. But as in the case with only a lower bound, we restrict our analysis to the target equilibrium.

In the target equilibrium, the average rate of inflation varies with the level at which the upper bound on interest rates is set.

\section{Lemma 1 (Inflation expectations with upper bound)}

If the upper bound on interest rates is set symmetrically to the lower bound around the neutral rate of interest $r^{*}$ and the intercept of the policy rate is equal to $r^{*}$, then inflation expectations are at target.

Proof: Due to the symmetry, it is easy to see that either both constraints are binding occasionally or none of the constraints are binding. Plugging $\theta_{0}=r^{*}$ and $r^{*}=\frac{1}{2}\left(i^{\mathrm{LB}}+i^{\mathrm{UB}}\right)$ into the above condition for inflation expectations delivers

$$
\mathbb{E}[\pi]=\frac{\alpha \kappa}{4 \theta_{\mu} \hat{\mu}}\left(-2 \theta_{E} \mathbb{E}[\pi]\right)\left(\left(i^{\mathrm{UB}}-i^{\mathrm{LB}}\right)-2 \theta_{\mu} \hat{\mu}\right)+\left(1+\alpha \kappa\left(1-\theta_{E}\right)\right) \mathbb{E}[\pi]
$$

As a result, the equation is linear in inflation expectations, and inflation expectations of zero are the unique equilibrium. If none of the constraints is binding, inflation expectations are determined by

$$
\mathbb{E}[\pi]=\left(1+\alpha \kappa\left(1-\theta_{E}\right)\right) \mathbb{E}[\pi]
$$

and, again, inflation expectations are at target.

Appendix A shows the graph analogous to Figure 1 for inflation expectations with an upper bound.

Weighing against the benefit of higher inflation expectations, the introduction of an upper bound on interest rates has the drawback of limiting the variance of interest rate policy. With an upper bound, the central bank finds itself constrained in stabilizing the effects of large positive supply and demand shocks. As a result, economic activity is more exposed to shocks and becomes more volatile. On net, the social loss is reduced relative to the case with discretion if the upper bound is set appropriately, as we discuss in more detail below. 


\subsection{Static: Dovish policies}

Optimal interest rate policy under discretion reacts to both supply and demand shocks. Due to occasional encounters with the lower bound, inflation expectations are below target. If the central bank responds less to shocks, it can reduce the probability of a binding lower bound. Specifically, the central bank lowers the response coefficients $\theta_{\mu}$ and $\theta_{\epsilon}$ while leaving all other parameters of the policy rule unchanged.

Smaller responses to shocks in the following period will result in, all else being equal, higher inflation expectations due to a smaller probability of reaching the lower bound. This benefit comes at the cost of suboptimally responding to shocks in the current period. Since the central bank aims to affect inflation expectations while reacting suboptimally in the current period, commitment is necessary to implement this policy rule. We investigate the effects of dovish policies on the social loss together with other static policies below.

\section{Average-inflation targeting}

This section consists of two parts. The first average-inflation targeting framework is static in that it retains the feature that inflation expectations are constant over time. Then we discuss dynamic Reifschneider-Williams rules in which the central bank conditions on past misses in setting its interest rate relative to the benchmark rule.

\subsection{Static average-inflation targeting}

For static average-inflation targeting, the central bank leaves the general form of its interest rate rule in (7) intact but adjusts the level $\theta_{0}$, as, for example, discussed in Reifschneider and Williams (2000). By changing the level of interest rates, the central bank can bring average inflation to its target rate. In particular, if the central bank lowers the intercept of the policy rate to

$$
\theta_{0}^{*}=r^{*}-\left(\sqrt{r^{*}-i^{L B}}-\sqrt{\theta_{\mu} \hat{\mu}}\right)^{2}<r^{*}
$$

inflation expectations are zero. ${ }^{8}$ All other coefficients in the interest rate rule remain unchanged relative to optimal policy under discretion.

\footnotetext{
${ }^{8}$ The intercept $\theta_{0}^{*}$ in equation (11) leads to zero average inflation whenever $0<\theta_{\mu}<\frac{\left(r^{*}-i^{\mathrm{LB}}\right)\left(\kappa^{2}(1+\alpha \kappa)+\lambda(1-\beta+\alpha \kappa)\right)^{2}}{\alpha^{2} \kappa^{2}\left(\kappa^{2}+\lambda\right)^{2} \bar{\mu}}$.
} 
As a result of this intervention, the central bank permanently provides more stimulus whenever it is unconstrained. It thus runs inflation above target whenever the lower bound permits, such that inflation is at target on balance. While inflation expectations rise in the target equilibrium due to the change in policy, they fall into the liquidity trap. Appendix B contains details.

\section{Proposition 1 (Optimal interest rate rule)}

The optimal interest rate rule lowers the intercept $\theta_{0}$ relative to the case under discretion such that average inflation is above target and leaves the responses to supply and demand shocks unchanged.

This proposition contains two important characterizations of the optimal rule.

First, the central bank would want to lower the intercept of its policy rule whenever unconstrained to provide extra stimulus relative to optimal policy under discretion. Interestingly, the central bank finds it optimal to lower the intercept to a point where the average inflation rate is above target in order to compensate for the asymmetry of the inflation and output gap distributions, which have a larger tail toward the downside.

Second, when the intercept of the rule is set optimally, the optimal response to shocks is the same as under discretionary policy. That is, there is no benefit from following a dovish policy response. As discussed earlier, dovish policies bring about welfare gains by raising inflation expectations. They achieve this outcome by lowering the probability of hitting the lower bound at the cost of insufficiently offsetting shocks today. If inflation expectations are already optimally set through the level of the interest rate rule, there is no need to incur the cost of allowing a greater passthrough of shocks in the current period.

These two predictions show that average-inflation targeting dominates dovish policies and brings about welfare gains. Since there is no need to engage in dovish policies for the optimally set level of the interest rate rule, we know that average-inflation targeting fares at least as well as dovish policies. In our further analysis, we focus on the case where the central bank aims for the average rate of inflation to be at target while keeping all other coefficients in the interest rate rule unchanged relative to the case under discretion.

\subsection{Dynamic: Reifschneider-Williams}

Reifschneider and Williams (2000) introduce the idea that the central bank keeps track of past misses in their desired interest rate relative to a benchmark rule due to the lower bound. A state variable $z_{t}$ aggregates past deviations of the interest rate from a reference interest rate which, in the original form, was specified to be a Taylor rule (see Taylor (1993)). 
To implement this idea in the context of our setup, we specify the reference interest rate rule to take the same form as optimal monetary policy under discretion in equation (7).

The sum of past misses $z_{t}$ follows the law of motion

$$
z_{t}=\rho z_{t-1}+i_{t-1}^{\mathrm{ref}}-i_{t-1}
$$

where $i_{t}$ is the actual policy rate and $i_{t}^{\text {ref }}$ is the reference rate. We augment the interest rate rule in equation (7) such that it can condition on past policy discrepancies

$$
i_{t}=\max \left\{\theta_{0}+\theta_{E} E_{t}\left[\pi_{t+1}\right]+\theta_{\mu} \mu_{t}+\theta_{\epsilon} \epsilon_{t}+\theta_{z} z_{t}, i^{\mathrm{LB}}\right\}
$$

The reference rate is defined as the rule with the same coefficients but absent the lower bound on interest rates and the conditioning on past misses. We leave all coefficients of the interest rate rule unchanged relative to optimal policy under discretion.

Two special cases are of interest. First, if the coefficient $\theta_{z}$ is zero, the rule coincides with that of equation (7) and optimal policy under discretion emerges. Second, if $\theta_{z}=\rho=1$, which is our main specification of the model, past misses are made up within one period whenever possible. ${ }^{9}$ A persistence of $\rho=1$ implies that all interest rate misses will have to be fully made up for. And we can interpret the coefficient $\theta_{z}$ as the fraction of past misses that are made up for each time the central bank is not constrained by the lower bound.

The interest rate rule in equation (13) operates by keeping rates "lower for longer" following periods of binding lower bounds. To see this, note that the only deviation of the interest rate rule from the benchmark rate can arise from a previous encounter with the lower bound. The accumulated shortfall $z_{t}$ lowers the nominal interest rate and supports, on average, above-target inflation.

With this interest rate rule in place, inflation expectations adjust dynamically. Since inflation will, on average, be higher following periods when the lower bound is binding, inflation expectations are higher during encounters with the lower bound. That is, the dynamic adjustment of the interest rate rule helps provide stimulus through higher inflation expectations precisely at a time when the central bank cannot provide any further stimulus through concurrent interest rate policy.

\section{Lemma 2 (Average rate of inflation under Reifschneider-Williams)}

When $\theta_{z}=\rho=1$, the Reifschneider-Williams policy rule leads to an average rate of inflation equal to the target rate.

\footnotetext{
${ }^{9}$ In a numerical analysis, $\theta_{z}=1$ turns out to be close to optimal.
} 
Appendix $\mathrm{C}$ contains a proof. The reason for the result in Lemma 2 is that missed interest rate cuts, and thus shortfalls in inflation, due to the lower bound are made up one-for-one in the future. The interest rate is thus, by design, set at the same average level as it would be under optimal monetary policy under discretion in the absence of a lower bound, a case where inflation expectations are at target.

Note that, under the Reifschneider-Williams rules, past misses in inflation do not have to be made up for other than the ones due to an inability to cut the policy rate. A negative supply shock will partially pass through to inflation but does not alter the future stance of monetary policy unless it causes the policy rate to be cut to the lower bound.

\section{Price-level targeting frameworks}

In this section, we evaluate policies that aim to stabilize a price level. The main difference between the price-level targeting frameworks and the average-inflation targeting policies of the previous section lies in the fact that price-level targeting makes up for past below-target inflation. Hence it does not treat bygones as bygones. We consider two alternatives. First, standard price-level targeting has been discussed as a policy framework within a New Keynesian model. It has been found to provide, under certain conditions, first-best macroeconomic outcomes (e.g., see Vestin (2006)). Second, we consider temporary price-level targeting that specifically addresses the issue of a binding lower bound on interest rates (for the proposals, see Evans (2010) and Bernanke (2017)).

\subsection{Dynamic: Price-level targeting}

Price-level targeting aims to achieve a stable path for a price. Whenever the price level falls below its target level, the central bank would keep rates lower than it otherwise would in order to bring about higher inflation temporarily until the shortfall is corrected. For a price level above target, the central bank would engage in contractionary monetary policy until the price level is back at target.

To formalize the policy framework, we introduce a price level whose logarithm $p_{t}$ evolves according to $p_{t}=p_{t-1}+\pi_{t} \cdot{ }^{10}$ We augment the interest rate rule in equation (7) with the log of the price level

$$
i_{t}=\max \left\{\theta_{0}+\theta_{E} \mathbb{E}_{t} \pi_{t+1}+\theta_{\epsilon} \epsilon_{t}+\theta_{\mu} \mu_{t}+\theta_{p} p_{t}, i^{L B}\right\} .
$$

\footnotetext{
${ }^{10}$ In practice, the central bank would keep track of the difference between the log price level and a reference level, for example, a price level that grows at the target inflation rate. In our setup, the reference price level is normalized to 1 such that its logarithm and associated inflation vanish from the equations.
} 
We implement this policy rule by keeping all the coefficients at the same level as in optimal monetary policy under discretion in equation (7) and varying the level of $\theta_{p}$.

As a result of this adjustment to the policy rule, inflation expectations become a function of the price level. Appendix D contains details on the algorithm and computation of the expectations function. It shows that inflation expectations are an increasing function of the log price level if $\theta_{p}$ is positive.

The mechanism by which inflation expectations vary with the price level can best be seen when considering a situation where the price is initially at its target level. Suppose that there is a shortfall in inflation relative to target due to, say, a very negative supply shock that pushes the nominal interest rate to the lower bound in the current period. As a result, the price level will fall below its target level and, due to its influence on the policy rate, will induce nominal interest rates to remain low in the following period. The anticipation of low rates in the following periods, and the accompanying higher inflation rates, will result in higher inflation expectations already in the current period. Through the forward-looking Phillips curve, higher inflation expectations have an accommodating effect on the economy in the current period. As a result, higher inflation expectations mitigate the deleterious effects of negative supply shocks and encounters with the lower bound.

Price-level targeting operates even when the lower bound on interest rates is not binding. When the price level is at target and a positive supply shock hits the economy, the central bank optimally allows the supply shock to partially pass through to inflation. As a result, however, the price level rises faster than its target value, prompting future contractionary policy. The policy does not treat bygones as bygones and makes up for all past misses of inflation from their target value. Through this mechanism, price-level targeting has been shown to mitigate the effects of supply shocks even in the absence of a lower bound on interest rates.

The nature of shocks is critical since optimal monetary policy under discretion already offsets demand shocks fully if the central bank is constrained in its policy setting. Supply shocks, however, affect the rate of inflation under optimal policy if the central banker puts weights on both inflation and real activity in its loss function, i.e., $\lambda>0$.

\subsection{Temporary price-level targeting}

As discussed earlier, price-level targeting changes interest rate setting by the central bank even in the absence of a lower bound on interest rates. Therefore, changing to price-level targeting is a substantial shift in policy relative to standard inflation targeting.

State-dependent price-level targeting can specifically address the effects of the lower bound on interest 
rates. Under this policy, the central bank follows standard inflation-targeting practices during normal times. An encounter with the lower bound would trigger an episode of temporary price-level targeting. The central bank would keep rates at the lower bound until the price level is back at target.

We implement this idea in a slightly generalized form. Policy is conducted according to the following interest rate rule:

$$
i_{t}= \begin{cases}\max \left\{\theta_{0}+\theta_{\mu} \mu_{t}+\theta_{\epsilon} \epsilon_{t}+\theta_{E} \mathbb{E}\left(\pi_{t+1} \mid \hat{p}_{t}=0\right), i^{\mathrm{LB}}\right\} & \text { if } p_{t-1}=0 \\ \max \left\{\theta_{0}+\theta_{\mu} \mu_{t}+\theta_{\epsilon} \epsilon_{t}+\theta_{E} \mathbb{E}\left(\pi_{t+1} \mid \hat{p}_{t}\right)+\theta_{p} \hat{p}_{t}, i^{\mathrm{LB}}\right\} & \text { if } \hat{p}_{t-1}<0 .\end{cases}
$$

We again use the same coefficients that we obtained for optimal monetary policy under discretion. We can adjust how much the interest rate responds to the deviations of the log price level from its targeting by varying the coefficient $\theta_{p}$.

If the value of the supply shock is below $\mu^{c}=\frac{{ }^{L B}-\theta_{0}-\theta_{E} \mathbb{E}\left[\pi_{t+1} \mid \hat{p}_{t}\right]-\theta_{p} \hat{p}_{t}}{\theta_{\mu}}$, the lower bound on interest rates binds. The (temporary) price level evolves according to:

$$
\hat{p}_{t}= \begin{cases}0 & \text { if } i_{t}>i^{\mathrm{LB}} \text { and } \hat{p}_{t-1}=0 \\ \min \left\{\hat{p}_{t-1}+\pi_{t}, 0\right\} & \text { if } i_{t}=i^{\mathrm{LB}} \text { or } \hat{p}_{t-1}<0\end{cases}
$$

This rule states that a temporary price-level targeting episode will be triggered by the policy rate hitting the lower bound on interest rates. During that episode, the interest rate rule conditions on a price-level target. The episode ends as soon as the price level is back at its target value. Similar to price-level targeting, inflation expectations become a function of the price level during temporary price-level targeting episodes. Appendix E describes the numerical algorithm to compute the expectation functions.

The specification in equation (15) generalizes the original proposals in the following way. If the responsiveness of interest rates to the price level, $\theta_{p}$, is infinite, interest rates will be at the lower bound whenever a temporary price-level episode has been triggered. If $\theta_{p}=0$, the policy is exactly the one described in standard inflation targeting.

The mechanism is similar to price-level targeting in that encounters with the lower bound are followed by periods of lower interest rates to make up for the shortfall in the price level. Contrary to price-level targeting, however, its temporary counterpart only reacts to shortfalls in inflation due to the lower bound and does not correct for periods of high inflation. 
As a result, the unconditional distributions of inflation and the output gap are asymmetric. Following an encounter with the lower bound on interest rates, temporary price-level targeting makes up for any change in inflation until the price level is back at its target value. The same inflation rate would not trigger a policy response outside of the price-level targeting regime. Due to this asymmetry, the average rate of inflation can differ from the target rate.

\section{Comparison of monetary policy frameworks}

This section compares the various monetary policy frameworks and explains how they affect inflation expectations and macroeconomic outcomes. We start by discussing the baseline calibration of the model that underlies the graphs we show. We split the discussions of static and dynamic frameworks since they have different effects on inflation expectations.

\subsection{Parameterization}

The goal of the calibration is to illustrate the key mechanisms with a set of paths for inflation and output gaps and compute social losses for the monetary policy frameworks. The main emphasis is on qualitative results and the model simulations are thus best thought of as an illustration of the model behavior.

We choose a baseline annual calibration with a parameterization of $\beta=0.99$ for the time preference factor, $\alpha=1.25$ for the coefficient on interest rates in the IS curve, and $\kappa=0.8$ for the slope of the Phillips curve. ${ }^{11}$ The natural rate of interest is set to $r^{*}=1$ such that all results are to be interpreted as percentage points. We choose a lower bound on interest rates of $i^{\mathrm{LB}}=-0.5$. In the baseline specification, the central bank puts a weight of $\lambda=0.25$ on stabilizing the output gap. We choose $\hat{\mu}=3.3$ for the model with supply shocks and $\hat{\epsilon}=3$ for the model with demand shocks. The volatility of supply shocks implies roughly a $25 \%$ chance of reaching the lower bound on interest rates when policy is conducted optimally under discretion.

Finally, for the Reifschneider-Williams rule, we choose a persistence of $\rho_{z}=1$ such that all misses of the interest rate rule have to be made up for. The corresponding interest rate rule has a coefficient of $\theta_{z}=1$ such that the central bank makes up for past misses within one period if the lower bound on interest rates permits.

\footnotetext{
${ }^{11} \mathrm{~A}$ different calibration might help in understanding the quantitative aspects of the model but that is not the focus of this paper. In particular, a flatter Phillips curve might lead to smaller effects on inflation.
} 

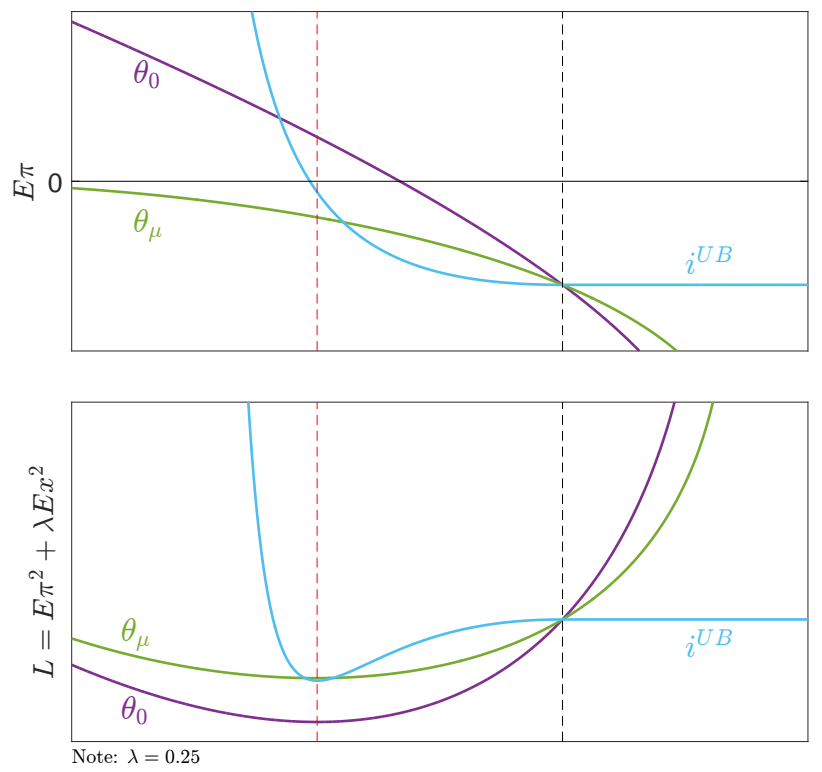

Figure 2: Inflation expectations (upper panel) and social losses (lower panel) under an upper bound on interest rates (light blue line), dovish policies (green line), and different intercepts for the policy rule (purple line) for changes in the corresponding parameter. The graphs are computed under the baseline specification with supply shocks only.

\subsection{Comparison of static frameworks}

We compare all of the three static frameworks — the upper bound on interest rates, dovish policies, and static average-inflation targeting-to optimal monetary policy under discretion. Therefore, we choose a setting where only supply shocks hit the economy. Figure 2 shows inflation expectations and social losses for the three policy frameworks.

The dashed black vertical line in Figure 2 shows the benchmark case of optimal policy under discretion, a special case for all of the three frameworks. Moving to the left varies the parameters for the different frameworks. For example, following the purple line in the upper panel to the left shows how inflation expectations rise when the central bank lowers the intercept of the policy rule. The changes in parameters for the three frameworks are normalized such that the minimal social loss occurs at the dashed red vertical line.

Figure 2 shows that static average-inflation targeting (SAIT) dominates both an optimally set upper bound on interest rates as well as an optimal dovish policy. The social loss is lower than for the other frameworks supported by inflation expectations running above target - even on average and not just whenever unconstrained. The reason is the asymmetry of the inflation distribution that prevails under average-inflation targeting. Note that inflation expectations are positive at the optimal intercept for the policy rule, denoted by the vertical red dashed line. 

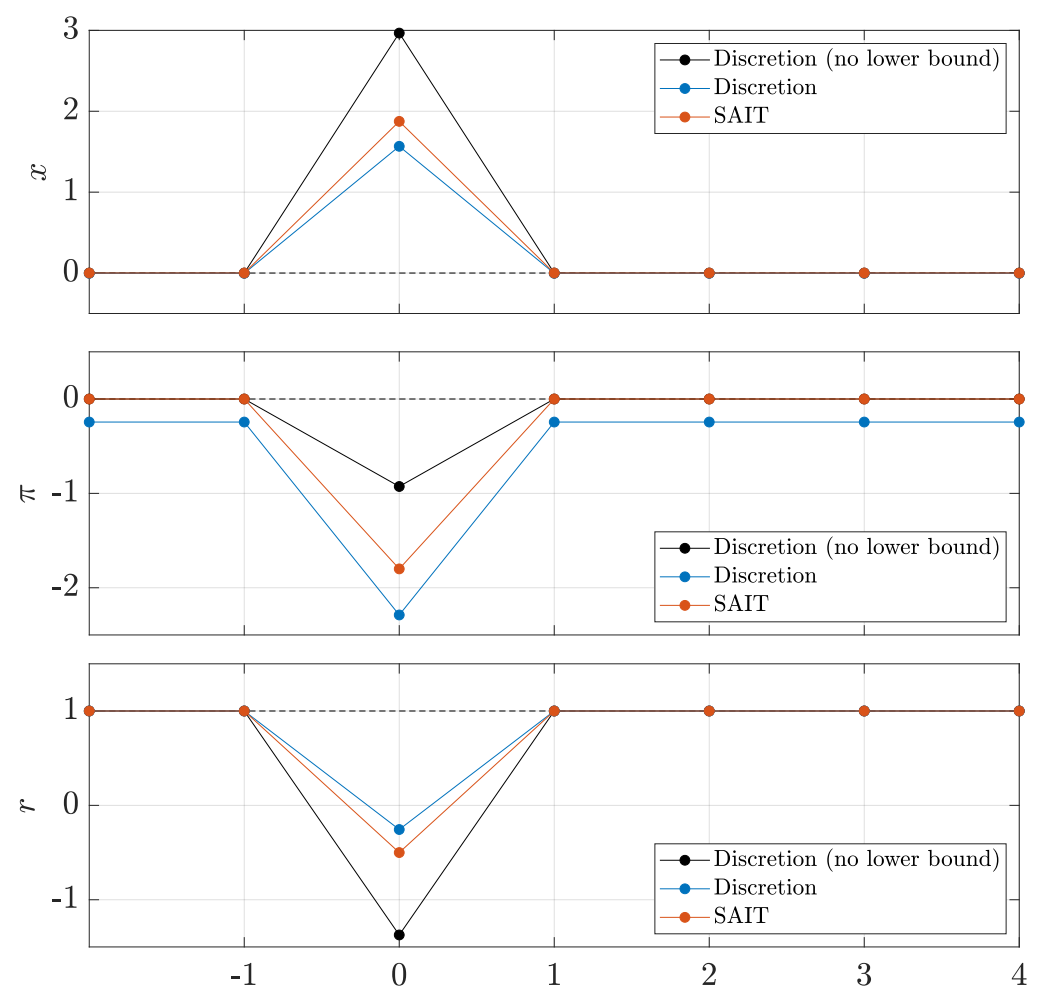

Figure 3: Impulse response functions under different policies in response to a negative supply shock $\mu_{0}=-\hat{\mu}$ at time zero for the output gap (upper panel), the rate of inflation (middle panel), and the real interest rate (lower panel). We used the benchmark calibration with $\lambda=0.25$.

To see the mechanics of the static average-inflation framework, Figure 3 plots impulse response functions under this policy and compares it with optimal monetary policy under discretion both in the absence and presence of a lower bound on interest rates. For all of these paths, a large negative supply shock of $\mu_{0}=-\hat{\mu}$ hits the economy at time zero, whereas the economy follows its average behavior at all other times. We therefore simulate the economy, impose the negative shock at time zero for each simulation, and average across all paths.

There are two differences in the economy's response to a negative supply shock under the different frameworks. First, the immediate impact varies under different policies. When there is no lower bound that can constrain the central bank, the central bank can offset the shock optimally by lowering the real interest rate. As a result, the output gap becomes positive while inflation is below target. Due to the i.i.d. nature of the shocks, the effects are purely temporary. Second, average inflation differs across the policies. While average-inflation targeting and optimal policy in the absence of a lower bound both keep inflation at target on average, optimal policy in the presence of a lower bound runs inflation expectations below target as discussed above. As a result of this lower level of inflation expectations, the impact on inflation is more severe. 

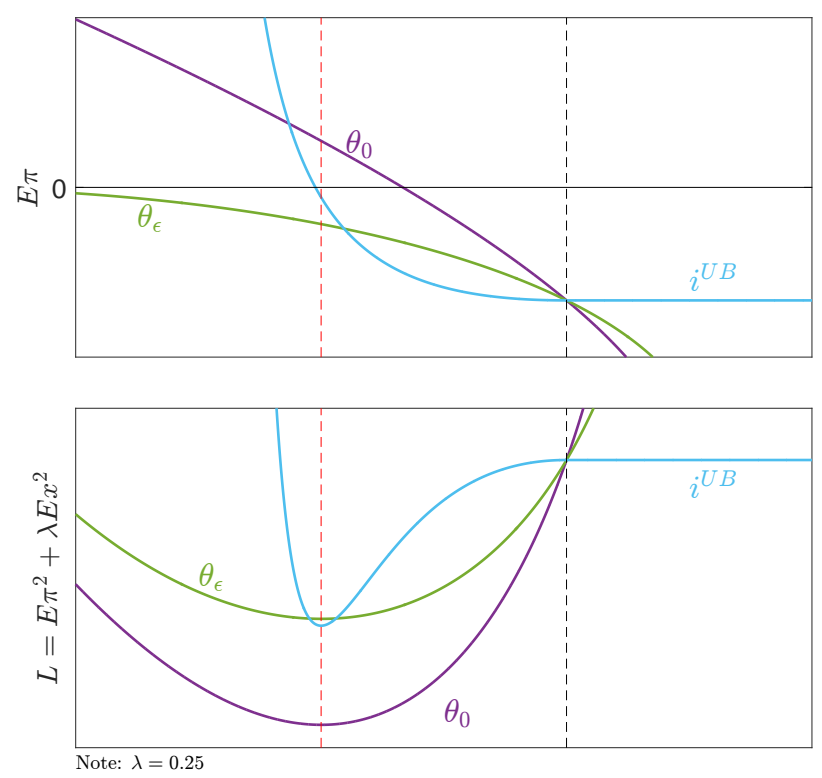

Figure 4: Inflation expectations (upper panel) and social losses (lower panel) under an upper bound on interest rates (light blue line), dovish policies (green line), and different intercepts for the policy rule (purple line) for changes in the corresponding parameter. The graphs are computed under the baseline specification with demand shocks only.

Figure 4 shows that the ranking among the policy options is the same when there are only demand shocks. Again, all of the policy rules lead to reductions in social losses. Average-Inflation targeting thereby dominates an upper bound on interest rates and dovish policies.

To see the mechanics of the policy frameworks with demand shocks, Figure 5 shows these impulse response functions for a negative demand shock at time 0 . Optimal policy under discretion in the absence of a lower bound calls for complete stabilization of the demand shock. It neutralizes the impact of the shock on inflation and the output gap by sharply reducing the real interest rate.

Whenever the central bank is constrained by the lower bound on interest rates, it cannot reduce real interest rates sufficiently to offset the shock. As a result, inflation falls below target on impact and the output gap is negative. However, due to higher inflation expectations under static average-inflation targeting, the contraction in inflation and real activity is less pronounced compared with optimal policy under discretion.

\subsection{The mechanics of the dynamic policy frameworks}

To illustrate and compare the different frameworks, we show the average paths for inflation, the price level, the output gap, and the real interest rate within the context of a model that features only supply shocks. Therefore, we simulate the model under the benchmark calibration and show average paths following a given shock realization. In this experiment, we show the mean of the unconditional distribution in period -1 and 

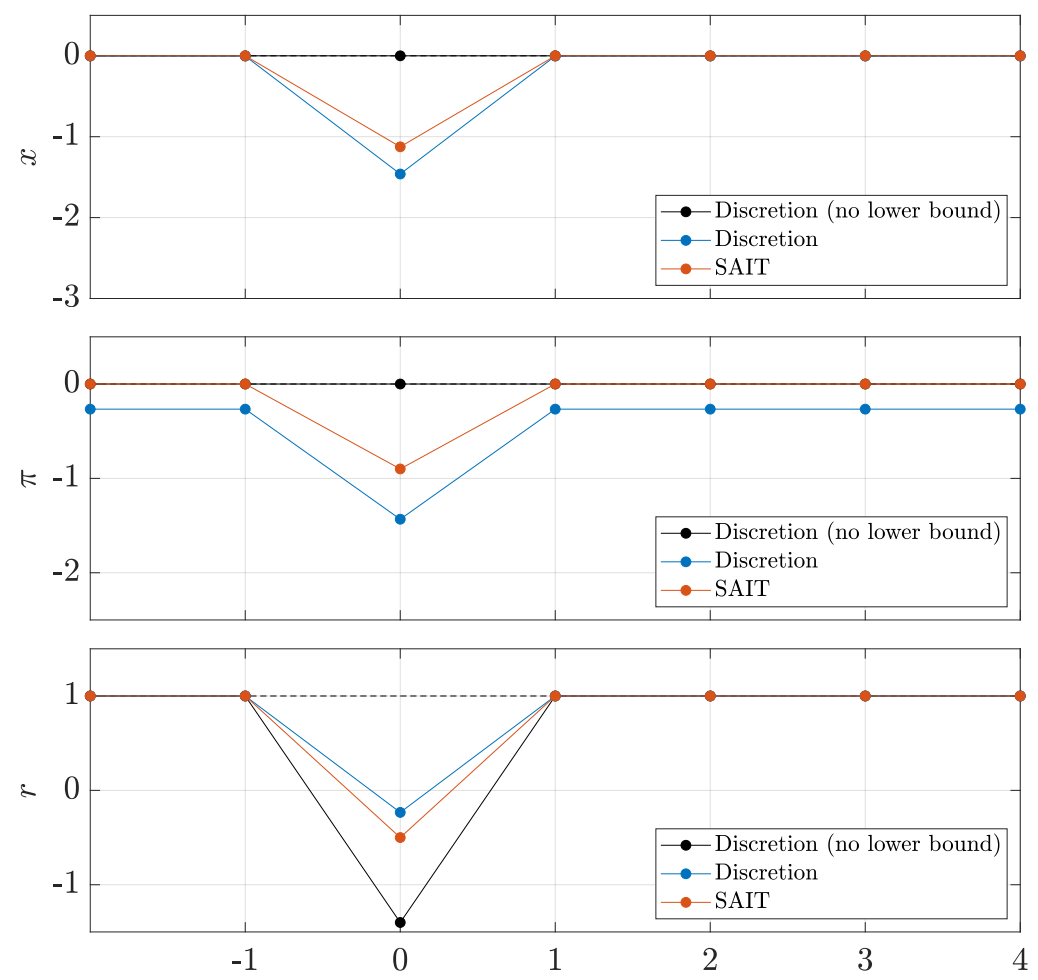

Figure 5: Impulse response functions under different policies in response to a negative demand shock $\epsilon_{0}=-\hat{\epsilon}$ at time zero for the output gap (upper panel), the rate of inflation (middle panel), and the real interest rate (lower panel). We used the benchmark calibration without supply shocks to parameterize the model.

pick a shock realization in period 0 . In all future periods, we average the responses across all simulated economies.

First, we show the response to a positive supply shock where $\mu_{0}=\hat{\mu}$. Since supply shocks are only partially offset by the central bank, they spill over to inflation and thus affect the price level. As shown in Figure 6, there are a number of differences among the various policies.

Period -1 shows that average inflation is negative when interest rates are set optimally under discretion. By design, inflation is at target for average-inflation targeting and the Reifschneider-Williams (RW) rule. Temporary price-level targeting (TPLT) features above-target inflation that leads to a positive drift in the price level (see lower left panel of Figure 6). The average rate of inflation under price-level targeting (PLT) is very close to target.

In response to the positive supply shock in period 0 , inflation rises under all policy frameworks. The main differences across the various policies is visible from period $1 \mathrm{on}$. Price-level targeting stands out in its policy response in that the central bank makes up for the high inflation with future below-target inflation in order to bring the price level back to its target. As shown in the lower left-hand panel, the price level reverts back to 
target while the shock is treated as a bygone under all other frameworks. Since we start from "normal" times where no temporary price-level episode has been triggered, the inflation path under temporary price-level targeting also displays only a temporary upswing in inflation.
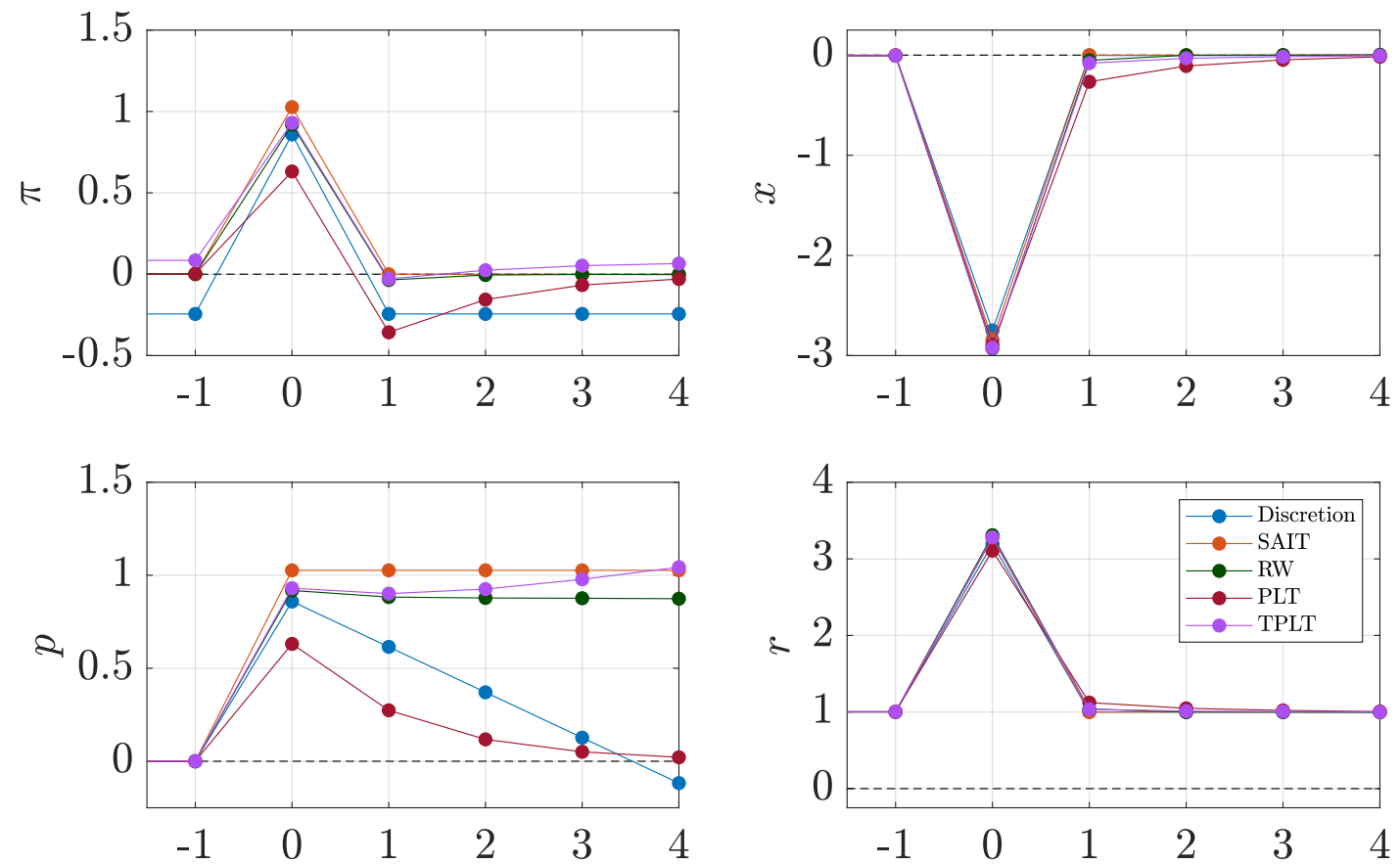

Figure 6: Impulse response functions under different dynamic policies in response to a positive supply shock at time $0, \mu_{0}=\hat{\mu}$ for inflation (upper left-hand panel), the price level (lower left-hand panel), the output gap (upper right-hand panel), and the real interest rate (lower right-hand panel). We used the benchmark calibration with supply shocks to parameterize the model.

Next we investigate the reponse to a single large negative supply shock in period zero that sends the policy rate to the lower bound. All further realizations of supply shocks are at their average values. There are significant differences in the response to this shock among the various policy frameworks, as Figure 7 demonstrates. For average-inflation targeting, the episode of the lower bound is purely temporary and does not affect inflation in subsequent periods. The path under the Reifschneider-Williams rule looks very different. Inflation falls signifcantly less due to higher inflation expectations. These inflation expectations have to be justified by higher inflation in the subsequent period. By that time, the shortfall in the interest rate cut due to the lower bound has been made up for and inflation from period two on is at target. Under (temporary) price-level targeting, encounters with the lower bound have a longer lasting impact. While higher inflation expectations reduce the impact of a negative shock, inflation remains above target for several 
periods thereafter.
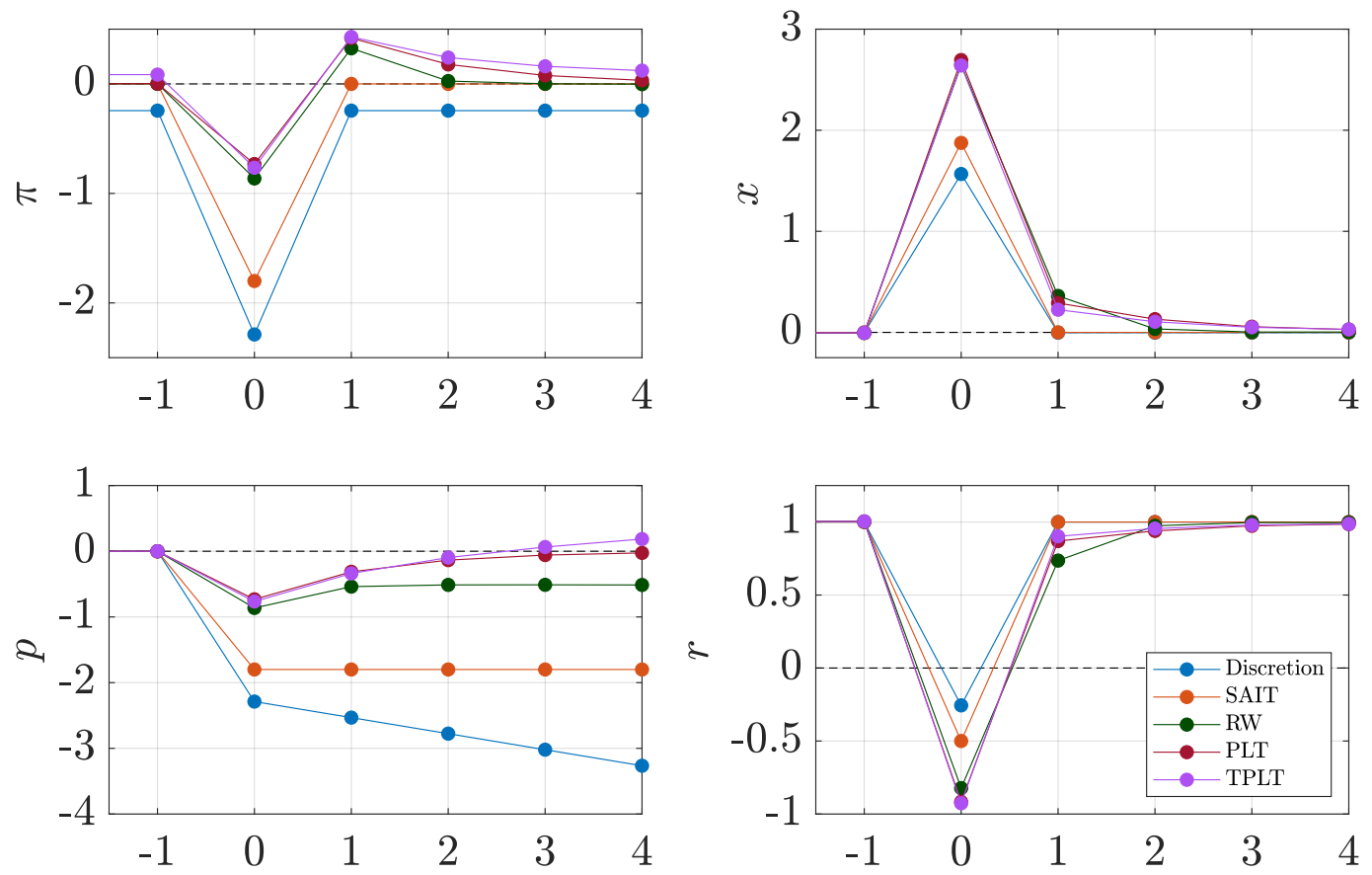

Figure 7: Impulse response functions under different dynamic policies in response to a negative supply shock at time 0 , $\mu_{0}=-\hat{\mu}$ for inflation (upper left-hand panel), the price level (lower left-hand panel), the output gap (upper right-hand panel), and the real interest rate (lower right-hand panel). We used the benchmark calibration without supply shocks to parameterize the model.

Figure 8 shows the responses to a negative demand shock that would be fully offset by optimal policy absent a lower bound on interest rates. When the central bank has to obey a lower bound on interest rates, a negative demand shock spills over to inflation and the output gap. Importantly, all dynamic policies achieve a rate of inflation close to the the target rate. Small discrepancies for the temporary price-level targeting rules are due to the asymmetry of the unconditional distribution we discussed earlier. Appendix F contains a list of moments for the unconditional distributions under various policy rules. The policies differ in the way they anchor inflation. While static and dynamic average-inflation targeting policies treat the shock to inflation and thus the price level as temporary, price-level targeting rules make up for past shortfalls.

Figure 8 shows the responses to a positive demand shock. Here, we start with the average of the unconditional distribution in period -1 and force a shock realization of $\epsilon_{0}=\hat{\epsilon}$ in period 0 for all simulated economies. As a result, inflation is higher for optimal policy under discretion and average-inflation targeting. This result emerges because inflation is above average during normal times. Reifschneider-Williams, on 

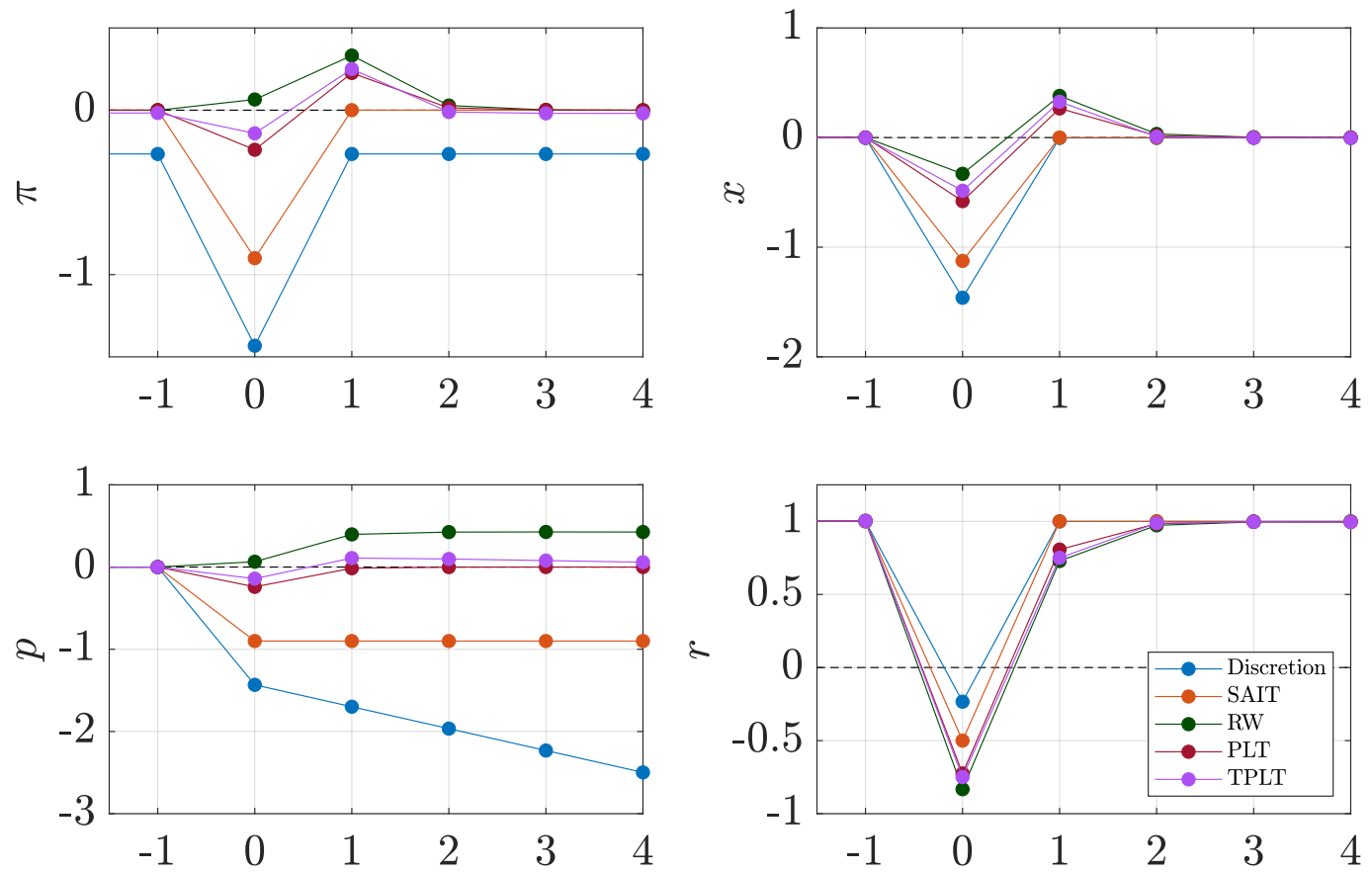

Figure 8: Impulse response functions under different dynamic policies in response to a negative demand shock at time $0, \epsilon_{0}=-\hat{\epsilon}$ for inflation (upper left-hand panel), the price level (lower left-hand panel), the output gap (upper right-hand panel), and the real interest rate (lower right-hand panel). We used the benchmark calibration without supply shocks to parameterize the model.

the other hand, can stabilize inflation during normal times just like an optimal rule would demand. The price-level targeting practices achieve almost full stabilization.

\subsection{Outcomes under different policy frameworks}

In this section, we investigate the effect of the various policy frameworks on social losses. Therefore, we first use the baseline model with supply shocks. For the Reifschneider-Williams rule, we compute the social loss under the parameterization $\rho_{z}=\theta_{z}=1$ such that all interest rate misses will be made up for in one period whenever feasible. And last, for price-level targeting, we compute the social loss as a function of the coefficient on the price-level using the same benchmark parameterization.

Figure 10 shows social losses for the different policies. Because only the price-level targeting and temporary price-level targeting frameworks are influenced by the parameter $\theta_{p}$, the lines for all other policies are flat. While the magnitude of the differences between the social losses vary with the parameterization, the ordering should be stable across a wide range of parameters. 

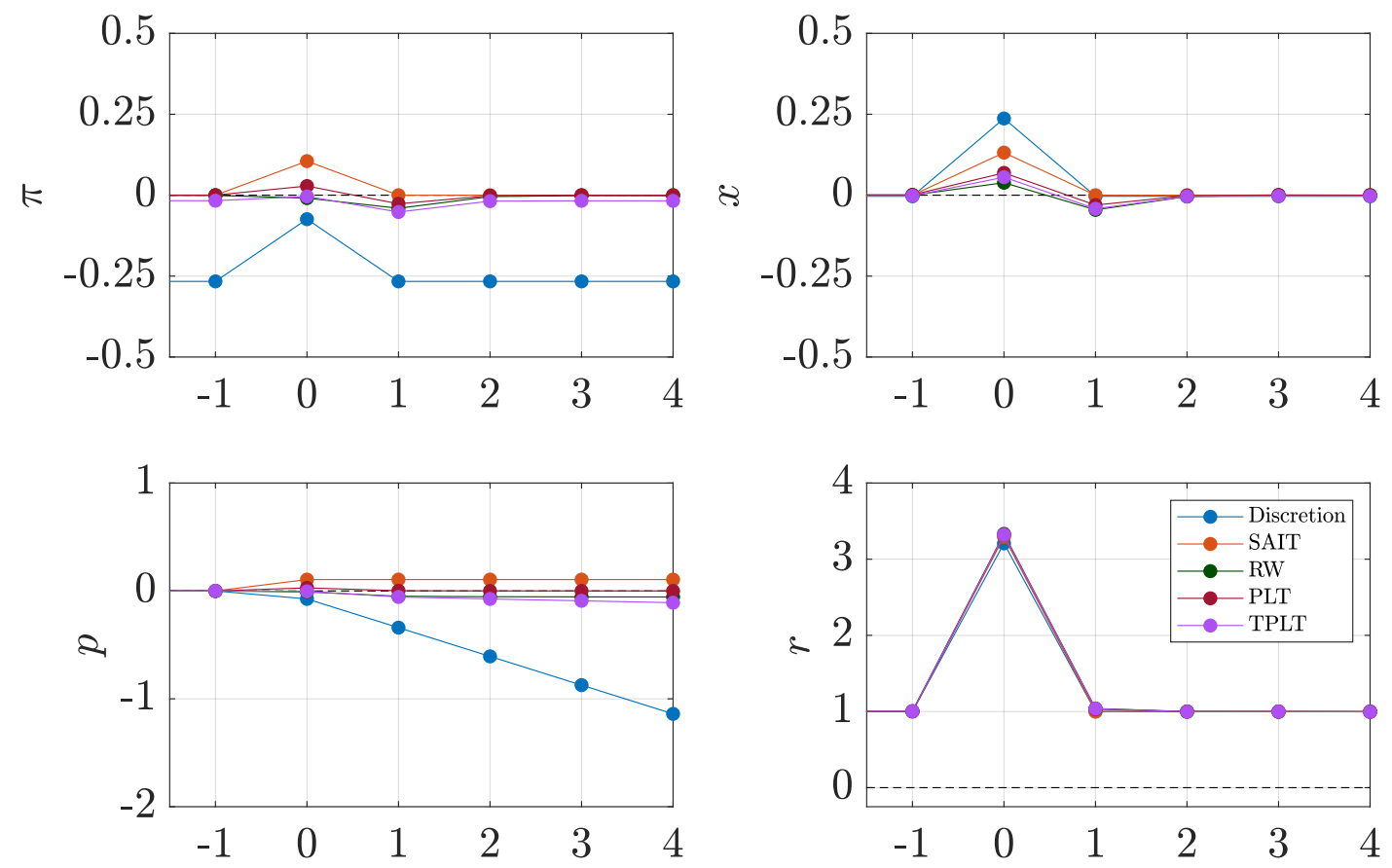

Figure 9: Impulse response functions under different dynamic policies in response to a positive demand shock at time $0, \epsilon_{0}=\hat{\epsilon}$ for inflation (upper left-hand panel), the price level (lower left-hand panel), the output gap (upper right-hand panel), and the real interest rate (lower right-hand panel). We used the benchmark calibration without supply shocks to parameterize the model.

Optimal monetary policy under discretion serves as our benchmark policy. Since this policy suffers from inefficiently low inflation expectations, average-inflation targeting can improve on social welfare. Due to the dynamic nature of policy adjustments, Reifschneider-Williams rules lower social losses further by raising inflation expectations at a time when they are needed the most.

Optimally parameterized price-level targeting dominates the other policy proposals in the case of supply shocks. As discussed before, this improvement in terms of social outcomes is due to the policy framework reacting more strongly to deviations of inflation from target irrespective of whether the nominal interest rate is at the lower bound or not. Temporary price-level targeting slightly dominates Reifschneider-Williams due to its ability to make up for shocks during temporary price-level targeting episodes, as we show below. In that sense, price-level targeting frameworks are a more fundamental departure from inflation targeting than the alternatives we discuss.

We contrast the findings for the model with supply shocks with the analogous results for a model with demand shocks in Figure 11. The mechanics for demand shocks are different since, even under optimal 


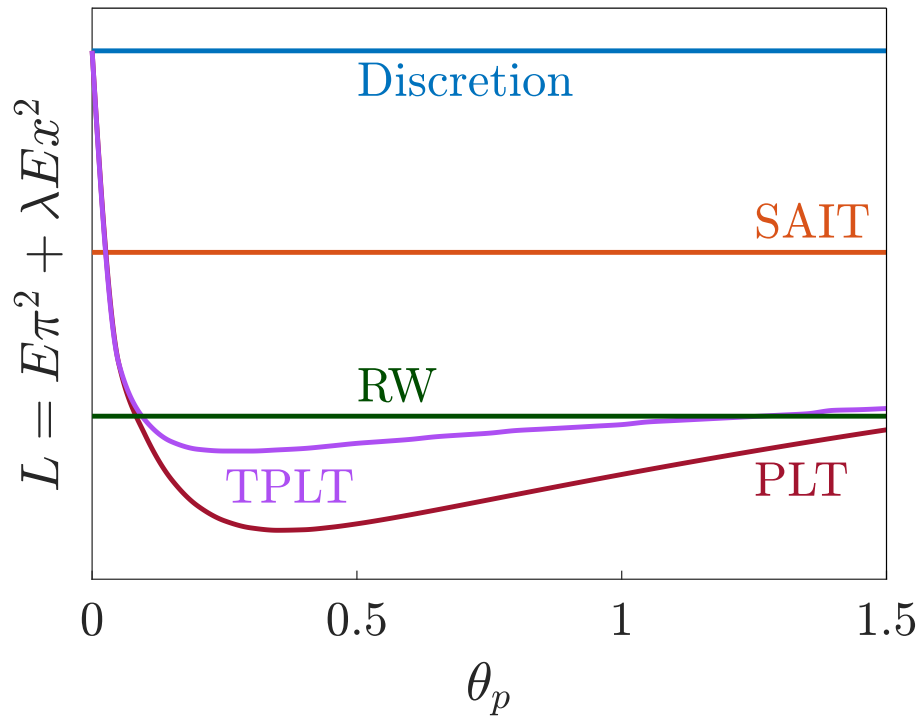

Figure 10: Social losses for different monetary policy frameworks as a function of the responsiveness of the interest rate rule to the price-level. The economy is hit only by supply shocks.

policy under discretion, demand shocks are fully offset unless the lower bound on interest rates becomes a binding constraint. In that sense, demand shocks give us a way to assess the influence of the lower bound on interest rates directly.

The ranking among the policy options is still the same for the static monetary policy frameworks. The bias in inflation expectations is directly related to the probability of hitting the lower bound. The mechanism behind the static policies is thus the same for demand and supply shocks.

The difference comes in for dynamic policies. The various optimized dynamic policies all yield the same loss in the case of demand shocks. Price-level targeting and temporary price-level targeting lead to virtually identical social losses since make-up strategies are only in effect after negative shocks when the temporary price-level target is triggered whereas positive shocks are fully offset through higher interest rates. Both policies lose some of the advantages they had in the presence of supply shocks relative to the ReifschneiderWilliams framework. Reifschneider-Williams is specifically designed to deal with issues associated with the lower bound on interest rates while (temporary) price-level targeting deals with these issues indirectly through a commitment to make up for the larger shortfalls in inflation cause by the lower bound. The results instead suggest that the additional gains under (temporary) price-level targeting for the case of supply shocks were, to a large extent, derived from policy commitments away from the lower bound. 


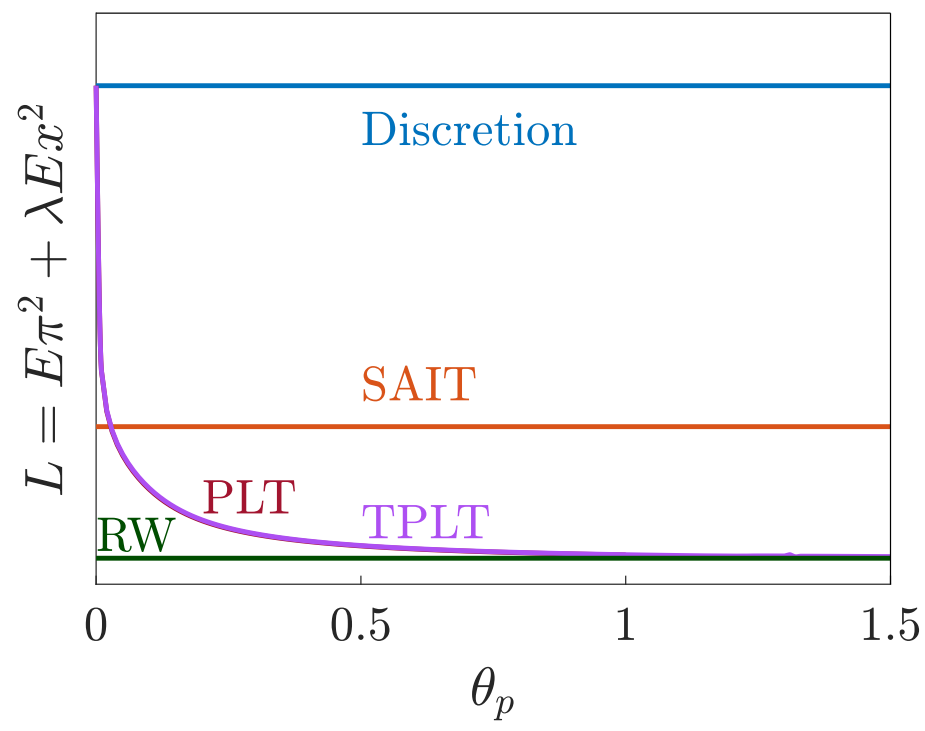

Figure 11: Social losses for different monetary policy frameworks as a function of the responsiveness of the interest rate rule to the price-level. The economy is hit only by demand shocks.

\section{Conclusion}

This paper analyzes various monetary policy frameworks and associated policy rules within a simple New Keynesian model with a lower bound on interest rates. We use the model to discuss both the mechanics of the policies as well as their implementation. We compare three broad classes of policy frameworks. Inflation expectations are the key vehicle through which the policy frameworks affect price setting and the macroeconomy. Dovish policies dampen the reaction to shocks and thereby bring about welfare gains.

Static average-inflation targeting eliminates the downward bias in inflation expectations. Once the level of the interest rate rule is set optimally, no further adjustment needs to be made to the responsiveness to shocks relative to optimal policy under discretion. Therefore, static average-inflation targeting dominates dovish policies.

Dynamic policy frameworks fare best. Reifschneider-Williams rules lead to an average inflation rate equal to target. Under this policy, the central bank promises to keep rates "lower for longer" and thus stimulates the economy precisely at a time when the central bank is constrained.

Particularly in the presence of supply shocks, price-level targeting rules lead to the lowest social losses. Because the difference with other frameworks is stronger in the presence of supply rather than demand shocks, we infer that some of these welfare benefits stem from policy commitments away from the lower 
bound.

While the focus of this paper is on the mechanisms of the various policies, further work is needed to evaluate their robustness by analyzing them within different economic models. Furthermore, a quantitative assessment of the policy frameworks within an estimated larger-scale DSGE model would be informative about the magnitude of the welfare gains under the various rules. 


\section{References}

Benhabib, Jess, Stephanie Schmitt-Grohé, and Martín Uribe, "The Perils of Taylor Rules," Journal of Economic Theory, 2001, $96(1), 40-69$.

Bernanke, Ben S., “Monetary Policy in a New Era," Peterson Institute for International Economics, 2017, pp. October $12-13$.

_ and Frederic S. Mishkin, "Inflation Targeting: A New Framework for Monetary Policy?," Journal of Economic Perspectives, Spring 1997, 11 (2), 97-116.

_, Michael T. Kiley, and John M. Roberts, “Monetary Policy Strategies for a Low-Rate Environment," forthcoming in American Economic Review, Papers and Proceedings, 2019.

Clarida, Richard, Jordi Gali, and Mark Gertler, "The Science of Monetary Policy: A New Keynesian Perspective," Journal of Economic Literature, 1999, 37 (4), 1661-1707.

Eggertsson, Gauti B. and Michael Woodford, "The Zero Interest-Rate Bound and Optimal Monetary Policy," Brookings Papers on Economic Activity, 2003, 2003 (1), 139-233.

Evans, Charles L., "Monetary policy in a low-inflation environment: Developing a state-contingent pricelevel target," speech at the Federal Reserve Bank of Boston's 55th Economic Conference, Revisiting Monetary Policy in a Low Inflation Environment, Boston, October 16, 2010.

Giannoni, Marc P., “Optimal interest-rate rules and inflation stabilization versus price-level stabilization," Journal of Economic Dynamics and Control, 2014, 41, 110-129.

Harrison, Richard, Martin Seneca, and Matt Waldron, "Monetary policy options in a 'low for long' era," mimeo, Bank of England, 2019.

Holston, Kathryn, Thomas Laubach, and John C. Williams, "Measuring the Natural Rate of Interest: International Trends and Determinants," Journal of International Economics, 2017, 108 (S1), S59-S75.

Koenig, Evan F., "Like a good neighbor: Monetary policy, financial stability, and the distribution of risk," International Journal of Central Banking, 2013, 9 (2), 57-82.

Laubach, Thomas and John C. Williams, "Measuring the Natural Rate of Interest Redux," Business Economics, 2016, 51, 257-267. 
Mendes, Rhys R., “Uncertainty and the Zero Lower Bound: A Theoretical Analysis,” Bank of Canada, 2011.

Mertens, Thomas M. and John C. Williams, "What to Expect from the Lower Bound on Interest Rates: Evidence from Derivatives Prices," Federal Reserve Bank of San Francisco, Working Paper 2018-03, 2018.

_ and _ , "Monetary Policy Frameworks and the Effective Lower Bound on Interest Rates," forthcoming in American Economic Review, Papers and Proceedings, 2019.

Nakata, Taisuke and Sebastian Schmidt, "Gradualism and Liquidity Traps," Review of Economic Dynamics, 2016, forthcoming.

Reifschneider, David L and John C. Williams, "Three lessons for monetary policy in a low-inflation era," Journal of Money, Credit and Banking, 2000, pp. 936-966.

Svensson, Lars E. O., “Price Level Targeting vs. Inflation Targeting: A Free Lunch?," Journal of Money, Credit, and Banking, 1999, 31, 277-295.

_ , "Monetary Policy Strategies for the Federal Reserve," mimeo, Stockholm School of Economics, 2019.

Taylor, John B., “What Would Nominal GDP Targeting Do to the Business Cycle," Carnegie-Rochester Conference Series on Public Policy, 1985, 22, 61-84.

_ , "Discretion versus policy rules in practice," Carnegie-Rochester Conference Series on Public Policy, 1993, 39, 195-214.

Vestin, David, "Price-level versus inflation targeting," Journal of Monetary Economics, 2006, 53, 1361-1376.

Woodford, Michael, Interest and Prices: Foundations of a Theory of Monetary Policy, Princeton University Press, 2003. 


\section{A Upper bound}

The various conditions determine whether a constraint never binds, $\mathbb{C}_{u}$, occasionally binds, $\mathbb{C}_{o}$, or always binds, $\mathbb{C}_{c}$. The specific conditions on the lower bound are

$$
\mathbb{C}_{u}^{\mathrm{LB}}=\left\{\frac{1}{\theta_{\mu}}\left(i^{\mathrm{LB}}-\theta_{0}-\theta_{E} \mathbb{E}\left[\pi_{t+1}\right]\right)<-\hat{\mu}\right\}
$$

for the lower bound to never bind,

$$
\mathbb{C}_{o}^{\mathrm{LB}}=\left\{-\hat{\mu} \leq \frac{1}{\theta_{\mu}}\left(i^{L B}-\theta_{0}-\theta_{E} \mathbb{E}\left[\pi_{t+1}\right]\right) \leq \hat{\mu}\right\}
$$

for the lower bound to occasionally bind, and

$$
\mathbb{C}_{c}^{\mathrm{LB}}=\left\{\frac{1}{\theta_{\mu}}\left(i^{\mathrm{LB}}-\theta_{0}-\theta_{E} \mathbb{E}\left[\pi_{t+1}\right]\right)>\hat{\mu}\right\}
$$

for the lower bound to always bind.

For the upper bound, the conditions are

$$
\mathbb{C}_{u}^{\mathrm{UB}}=\left\{\frac{1}{\theta_{\mu}}\left(i^{U B}-\theta_{0}-\theta_{E} \mathbb{E}\left[\pi_{t+1}\right]\right)>\hat{\mu}\right\}
$$

for the upper to never bind,

$$
\mathbb{C}_{o}^{\mathrm{UB}}=\left\{-\hat{\mu} \leq \frac{1}{\theta_{\mu}}\left(i^{U B}-\theta_{0}-\theta_{E} \mathbb{E}\left[\pi_{t+1}\right]\right) \leq \hat{\mu}\right\}
$$

for the upper bound to occasionally bind, and

$$
\mathbb{C}_{c}^{\mathrm{UB}}=\left\{\frac{1}{\theta_{\mu}}\left(i^{U B}-\theta_{0}-\theta_{E} \mathbb{E}\left[\pi_{t+1}\right]\right)<-\hat{\mu}\right\}
$$

for the upper bound to always bind.

Computing inflation expectations under the various scenarios delivers the graph of expected inflation as a function of expected inflation in the subsequent period shown in Figure 12. 


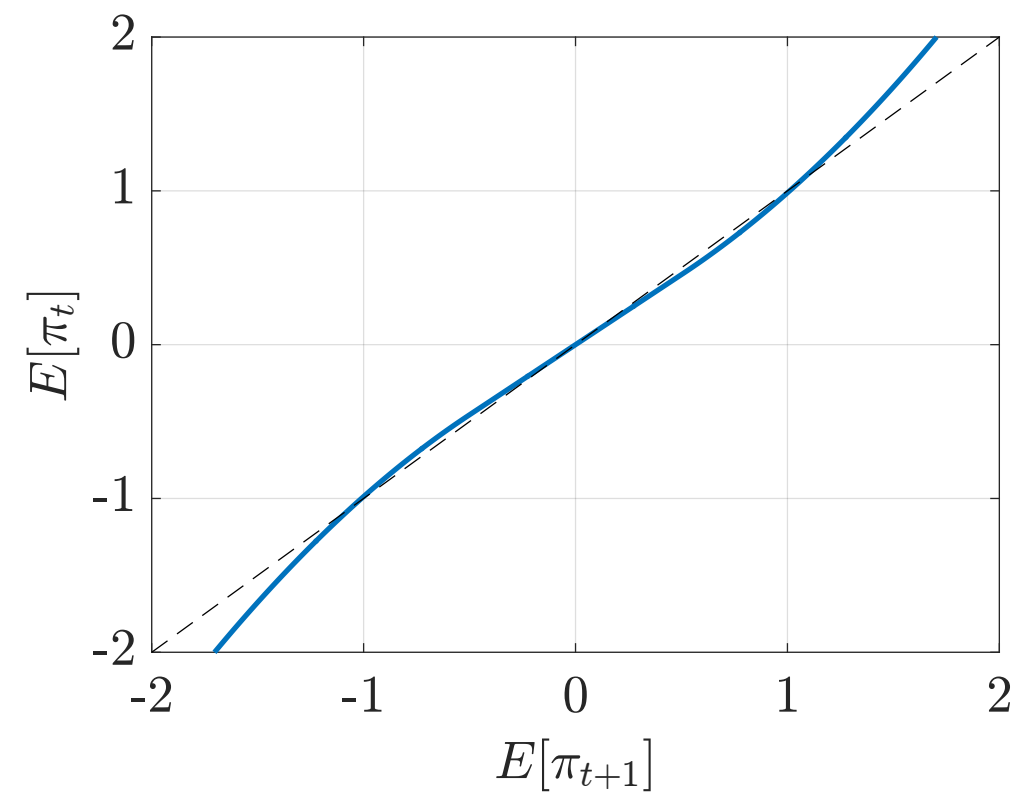

Figure 12: Expected inflation in the current period as a function of expected inflation in the following period. Parameter values are set to $\alpha=1.25, \kappa=0.8, \beta=0.99, r^{*}=1, \lambda=0.25, i^{L B}=-0.5$, and $i^{\mathrm{UB}}=2.5$. The support for supply shocks is $\hat{\mu}=3.3$ and there are no demand shocks, i.e., $\hat{\epsilon}=0$. Intersections with the dashed 45 -degree line represent steady states. The coefficients in the policy rule are those of optimal monetary policy under discretion.

\section{B Static average-inflation targeting}

When adjusting the level of interest rates such that average inflation is at target, inflation expectations fall into the liquidity trap equilibrium. Figure 13 shows the mapping from next period's expected inflation to the current period's expected inflation.

\section{Reifschneider-Williams rule}

\section{C.1 Proof of Lemma 2}

Proof: Iterating the IS curve in equation (2) forward results in

$$
x_{t}=\epsilon_{t}-\alpha \sum_{s=t}^{\infty} \mathbb{E}_{t}\left[i_{s}-\mathbb{E}_{s} \pi_{s+1}-r^{*}\right]
$$

Taking unconditional expectations on both sides delivers

$$
\mathbb{E} x_{t}=-\alpha \sum_{s=t}^{\infty} \mathbb{E}\left[i_{s}-\mathbb{E}_{s} \pi_{s+1}-r^{*}\right]
$$




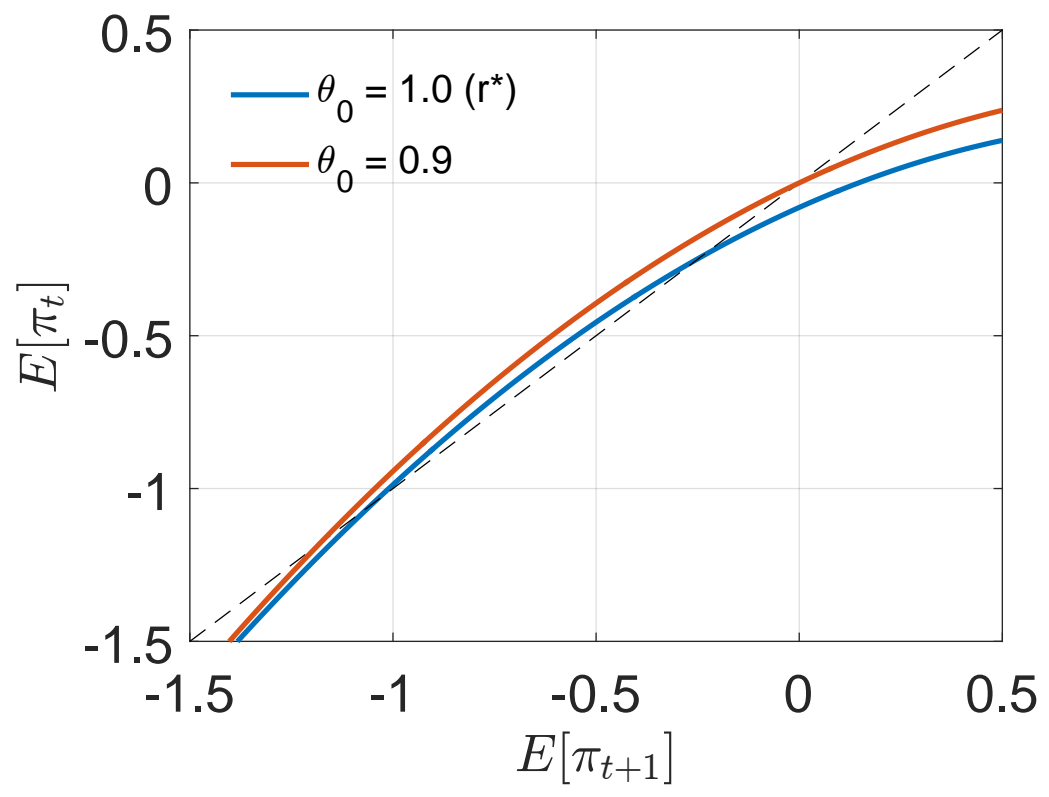

Figure 13: Expected inflation in the current period as a function of expected inflation in the following period. Parameter values are set to $\alpha=1.25, \kappa=0.8, \beta=0.99, r^{*}=1, \lambda=0.25$, and $i^{L B}=-0.5$. The support for supply shocks is $\hat{\mu}=3.3$ and there are no demand shocks, i.e., $\hat{\epsilon}=0$. Intersections with the dashed 45-degree line represent steady states. The coefficients in the policy rule are those of optimal monetary policy under discretion, except $\theta_{0}$ that is set according to equation (11).

By design, the Reifschneider-Williams rule delivers an average nominal interest rate equal to $r^{*}$. This result derives from the fact that the reference nominal interest rate $i_{t}^{\text {ref }}$ in equation (13) has $r^{*}$ as its intercept and all shortfalls in interest rate cuts are made up for by design. Plugging in $\mathbb{E}\left[i_{s}\right]=\mathbb{E}\left[i_{s}^{\text {ref }}\right]=r^{*}$ in the previous equation shows that the output gap is given by

$$
\mathbb{E} x_{t}=\alpha \sum_{s=t}^{\infty} \mathbb{E}\left[\pi_{s+1}\right] \text {. }
$$

The only non-explosive solution has an average inflation rate at target, i.e. $\mathbb{E}\left[\pi_{s}\right]=0$.

\section{C.2 Algorithm for Reifschneider-Williams rules}

We show the algorithm for the case of supply shocks in this section and the case of demand shocks works analogously. The model with suppy shocks only for the Reifschneider-Williams rule can be summarized by 
the following equations:

$$
\begin{aligned}
& x_{t}=-\alpha\left(i_{t}-\mathbb{E}_{t}\left(\pi_{t+1}\right)-r^{*}\right)+\mathbb{E}_{t}\left(x_{t+1}\right) \\
& \pi_{t}=\beta \mathbb{E}_{t}\left(\pi_{t+1}\right)+\kappa x_{t}+\mu_{t} \\
& i_{t}^{\mathrm{ref}}=\theta_{0}+\theta_{\mu} \mu_{t}+\theta_{E} \mathbb{E}_{t}\left(\pi_{t+1}\right) \\
& i_{t}=\max \left(i_{t}^{\mathrm{ref}}+\theta_{z} z_{t}, i^{\mathrm{LB}}\right) \\
& \tilde{i}_{t}=i_{t}^{\mathrm{ref}}-i_{t} \\
& z_{t+1}=z_{t}+\tilde{i}_{t}
\end{aligned}
$$

The algorithm approximates and stores the following objects:

- One-period-ahead expected inflation: $g_{\pi}(z)=\mathbb{E}\left[\pi_{t+1} \mid z_{t+1}=z\right]$

- One-period-ahead expected output gap: $g_{x}(z)=\mathbb{E}\left[x_{t+1} \mid z_{t+1}=z\right]$

- Realized Taylor rule deviation $f_{\tilde{i}}(\mu, z)=\tilde{i}_{t} \mid \mu_{t}=\mu, z_{t}=z$

- Realized inflation $f_{\pi}(\mu, z)=\pi_{t} \mid \mu_{t}=\mu, z_{t}=z$

- Realized output gap $f_{x}(\mu, z)=x_{t} \mid \mu_{t}=\mu, z_{t}=z$

To solve the model, we approximate these functions using linear interpolation and use the following iterative algorithm to solve for the functions' values at points along the following grids for $z$ and $\mu$ (respectively):

- $\mathcal{Z}$ : 101 equally spaced points between -10 and 0.

- $\mathcal{M}$ : 201 equally spaced points between $-\hat{\mu}$ and $\hat{\mu}$.

\section{Algorithm}

1. Initialize inflation expectations $g_{\pi}^{(0)}(z):=0$ for all $z \in \mathcal{Z}$.

2. Given the approximation of one-period-ahead inflation expectations $\left\{g_{\pi}^{(j-1)}(z) \mid z \in \mathcal{Z}\right\}$ from the previous iteration, solve the following fixed-point problem at each pair of gridpoint values $\{(\mu, z) \mid \mu \in \mathcal{M}, z \in \mathcal{Z}\}$ in order to update the approximation of the realized Taylor rule deviation $f_{\tilde{i}}^{(j)}(\mu, z)$ :

$$
f_{\tilde{i}}^{(j)}(\mu, z)=\left(\theta_{0}+\theta_{\mu} \mu+\theta_{E} g_{\pi}^{(j-1)}\left(z+f_{\tilde{i}}^{(j)}(\mu, z)\right)\right)-\max \left(\theta_{0}+\theta_{\mu} \mu+\theta_{E} g_{\pi}^{(j-1)}\left(z+f_{\tilde{i}}^{(j)}(\mu, z)\right)+\theta_{z} z, i^{L B}\right) .
$$


3. Given approximations for the realized Taylor rule deviation $\left\{f_{\tilde{i}}^{(j)}(\mu, z) \mid \mu \in \mathcal{M}, z \in \mathcal{Z}\right\}$ and expectations $\left\{g_{\pi}^{(j-1)}(z) \mid z \in \mathcal{Z}\right\},\left\{g_{x}^{(j-1)}(z) \mid z \in \mathcal{Z}\right\}$ from the previous iteration, at each pair of gridpoint values $\{(\mu, z) \mid \mu \in \mathcal{M}, z \in \mathcal{Z}\}$ update the following approximations:

$$
\begin{aligned}
& f_{i}^{(j)}(\mu, z):=\max \left(\theta_{0}+\theta_{\mu} \mu+\theta_{E} g_{\pi}^{(j-1)}\left(z+f_{\tilde{i}}^{(j)}(\mu, z)\right)+\theta_{z} z, i^{L B}\right) \\
& f_{x}^{(j)}(\mu, z):=-\alpha\left(f_{i}^{(j)}(\mu, z)-g_{\pi}^{(j-1)}\left(z+f_{\tilde{i}}^{(j)}(\mu, z)\right)-r^{*}\right)+g_{x}^{(j-1)}\left(z+f_{\tilde{i}}^{(j)}(\mu, z)\right) \\
& f_{\pi}^{(j)}(\mu, z):=\beta g_{\pi}^{(j-1)}\left(z+f_{\tilde{i}}^{(j)}(\mu, z)\right)+\kappa f_{x}^{(j)}(\mu, z)+\mu
\end{aligned}
$$

4. Update approximations for one-period-ahead expectations $\left\{g_{\pi}^{(j)}(z) \mid z \in \mathcal{Z}\right\}$ and $\left\{g_{x}^{(j)}(z) \mid z \in \mathcal{Z}\right\}$ for all $z \in \mathcal{Z}$, using the following discrete sum approximation for integration over $\mu$ :

$$
\begin{aligned}
& g_{\pi}^{(j)}(z)=\sum_{\mu \in \mathcal{M}} f_{\pi}^{(j)}(\mu, z) \\
& g_{x}^{(j)}(z)=\sum_{\mu \in \mathcal{M}} f_{x}^{(j)}(\mu, z) .
\end{aligned}
$$

5. Iterate steps 2-4 until all of the approximations have converged.

The Reifschneider-Williams rule results in inflation expectations as a function of the cumulative shortfall in interest rate cuts.

\section{Algorithm for price-level targeting}

For price-level targeting, we again present the algorithm for the case of supply shocks only. The algorithm for the case of demand shocks works analogously. Therefore, we use the following set of equations for the model:

$$
\begin{aligned}
& x_{t}=-\alpha\left(i_{t}-\mathbb{E}_{t}\left[\pi_{t+1}\right]-r^{*}\right)+\mathbb{E}_{t}\left[x_{t+1}\right] \\
& \pi_{t}=\beta E_{t}\left(\pi_{t+1}\right)+\kappa x_{t}+\mu_{t} \\
& i_{t}=\max \left\{\theta_{0}+\theta_{\mu} \mu_{t}+\theta_{E} \mathbb{E}_{t}\left[\pi_{t+1}\right]+\theta_{p} p_{t}, i^{\mathrm{LB}}\right\} \\
& p_{t}=p_{t-1}+\pi_{t} .
\end{aligned}
$$

The numerical procedure approximates and stores the following objects: 
- One-period-ahead expected inflation: $g_{\pi}(p)=\mathbb{E}\left[\pi_{t+1} \mid p_{t}=p\right]$

- One-period-ahead expected output gap: $g_{x}(p)=\mathbb{E}\left[x_{t+1} \mid p_{t}=p\right]$

- Realized inflation $f_{\pi}(\mu, p)=\pi_{t} \mid \mu_{t}=\mu, p_{t-1}=p$

- Realized output gap $f_{x}(\mu, p)=x_{t} \mid \mu_{t}=\mu, p_{t-1}=p$

To solve the model, we approximate these functions using interpolation and use the following iterative algorithm to solve for the functions' values at points along the following grids for $p$ and $\mu$ (respectively):

- $\mathcal{P}$ : the union of the following evenly spaced grids (intended to give a high density of gridpoints around $p=0)$ :

1. $\{-70,-65, \ldots, 65,70\}$

2. $\{-20,-19, \ldots, 19,20\}$

3. $\{-5,-4.75, \ldots, 4.75,5\}$

4. $\{-1,-0.9, \ldots, 0.9,1\}$

- $\mathcal{M}$ : 201 equally spaced points between $-\hat{\mu}$ and $\hat{\mu}$

\section{Algorithm}

1. Initialize inflation expectations $g_{\pi}^{(0)}(p):=0$ for all $p \in \mathcal{P}$.

2. Given the approximations of one-period-ahead expectations for inflation $\left\{g_{\pi}^{(j-1)}(p) \mid p \in \mathcal{P}\right\}$ and the output gap $\left\{g_{x}^{(j-1)}(p) \mid p \in \mathcal{P}\right\}$ from the previous iteration, solve the following fixed point problem at each pair of gridpoint values $\{(\mu, p) \mid \mu \in \mathcal{M}, p \in \mathcal{P}\}$ in order to update the approximation of realized inflation $f_{\pi}^{(j)}(\mu, p):^{12}$

$$
\begin{aligned}
f_{\pi}^{(j)}(\mu, p)= & \kappa\left(-\alpha\left(\max \left(\theta_{0}+\theta_{\mu} \mu_{t}+\theta_{E} g_{\pi}^{(j-1)}\left(p+f_{\pi}^{(j)}(\mu, p)\right)+\theta_{p} p, i^{L B}\right)-r^{*}\right)+g_{x}^{(j-1)}\left(p+f_{\pi}^{(j)}(\mu, p)\right)\right) \\
& +(\alpha \kappa+\beta) g_{\pi}^{(j-1)}\left(p+f_{\pi}^{(j)}(\mu, p)\right)+\mu .
\end{aligned}
$$

\footnotetext{
${ }^{12}$ Note that the equations determining the nominal interest rate and output gap have been substituted into the equation determining inflation, so that realized inflation is the only endogenous time $t$-variable that appears in the expression.
} 
3. Given approximations to realized inflation $\left\{f_{\tilde{i}}^{(j)}(\mu, p) \mid \mu \in \mathcal{M}, p \in \mathcal{P}\right\}$ and expectations $\left\{g_{\pi}^{(j-1)}(p) \mid p \in \mathcal{P}\right\}$, $\left\{g_{x}^{(j-1)}(p) \mid p \in \mathcal{P}\right\}$ from the previous iteration, at each pair of gridpoint values $\{(\mu, p) \mid \mu \in \mathcal{M}, p \in \mathcal{P}\}$ update the approximation for the realized output gap $f_{x}^{(j)}(\mu, p)$ :

$$
\begin{aligned}
f_{x}^{(j)}(\mu, p):= & -\alpha\left(\max \left(\theta_{0}+\theta_{\mu} \mu_{t}+\theta_{E} g_{\pi}^{(j-1)}\left(p+f_{\pi}^{(j)}(\mu, p)\right)+\theta_{p} p, i^{L B}\right)-g_{\pi}^{(j-1)}\left(p+f_{\pi}^{(j)}(\mu, p)\right)-r^{*}\right) \\
& +g_{x}^{(j-1)}\left(p+f_{\pi}^{(j)}(\mu, p)\right)
\end{aligned}
$$

4. Update approximations for one-period-ahead expectations $\left\{g_{\pi}^{(j)}(p) \mid p \in \mathcal{P}\right\}$ and $\left\{g_{x}^{(j)}(p) \mid p \in \mathcal{P}\right\}$ for all $p \in \mathcal{P}$, using the following discrete sum approximation for integration over $\mu$ :

$$
\begin{aligned}
& g_{\pi}^{(j)}(p)=\sum_{\mu \in \mathcal{M}} f_{\pi}^{(j)}(\mu, p) \\
& g_{x}^{(j)}(p)=\sum_{\mu \in \mathcal{M}} f_{x}^{(j)}(\mu, p) .
\end{aligned}
$$

5. Iterate steps 2-4 until all of the approximations have converged.

\section{E Temporary price-level targeting}

As in the other cases, we focus on the case of supply shocks only. The algorithm for the case with demand shocks works in the same way.

Policy is conducted according to the following interest rate rule:

$$
i_{t}= \begin{cases}\theta_{0}+\theta_{\mu} \mu_{t}+\theta_{E} \mathbb{E}\left[\pi_{t+1} \mid p_{t}=0\right] & \text { if } \mu_{t}>\mu^{c} \text { and } p_{t-1}=0 \\ i^{L B} & \text { if } \mu_{t} \leq \mu^{c} \text { or } p_{t-1}<0 .\end{cases}
$$

The "cutoff" supply shock value is defined as $\mu^{c} \equiv \frac{i^{L B}-\theta_{0}-\theta_{E} \mathbb{E}\left[\pi_{t+1} \mid p_{t}=0\right]}{\theta_{\mu}}$. The (temporary) price level evolves according to:

$$
p_{t}= \begin{cases}0 & \text { if } \mu_{t}>\mu^{c} \text { and } p_{t-1}=0 \\ \min \left(p_{t-1}+\pi_{t}, 0\right) & \text { if } \mu_{t} \leq \mu^{c} \text { or } p_{t-1}<0 .\end{cases}
$$

In words: when $\mu_{t} \leq \mu^{c}$, the nominal interest rate will surely be constrained if PLT is not initiated; when a negative shock of this magnitude occurs, the policymaker fixes $i_{t}=i^{L B}$ and initiates PLT, keeping the interest 
rate at the lower bound until the price level returns to its level in the period before the shock (i.e., until $p_{t}=0$ ).

This rule induces discontinuities in both realized and expected inflation. In particular, when $p_{t-1}=0$ (PLT has not already been initiated), $\pi_{t}$ is higher when $\mu_{t}=\mu^{c}-\epsilon$ than when $\mu_{t}=\mu^{c}+\epsilon$, since the former shock is just big enough to trigger a TPLT "episode" and deliver stimulus through a guarantee of low future interest rates. Similarly, $\mathbb{E}_{t}\left[\pi_{t+1} \mid p_{t}=-\epsilon\right]$ is much larger than $\mathbb{E}_{t}\left[\pi_{t+1} \mid p_{t}=0\right]$ since a TPLT "episode" is initiated only in the former case.

The following page displays plots of the solutions for expected and realized inflation, as well as sample paths for inflation, the nominal interest rate, the temporary price level, and the shocks $\mu$.

The horizontal lines in the interest rate and shock charts below denote $i^{L B}$ and $\mu^{c}$, respectively. Yellow dots in the interest rate chart denote periods where $i_{t}=i^{L B}$, while red dots denote periods where $p_{t}<0$.

\section{F The unconditional distribution of inflation and the output gap}

This section presents a list of moments for the unconditional distributions of inflation and the output gap under various policy rules. Table 1 contains a list of moments for the model with supply shocks, while Table 2 shows the analogous statistics for the model with demand shocks.

\begin{tabular}{l|rrrrrr} 
& $\begin{array}{c}\text { Discretion } \\
\text { (no lower bound) }\end{array}$ & Discretion & $\begin{array}{c}\text { SAIT } \\
(E \pi=0)\end{array}$ & RW & PLT & TPLT \\
\hline \hline $\mathbb{E}\left(\pi_{t}\right)$ & 0.000 & -0.244 & 0.000 & 0.000 & 0.002 & 0.083 \\
$\mathbb{V}\left(\pi_{t}\right)$ & 0.287 & 0.675 & 0.501 & 0.282 & 0.191 & 0.239 \\
$\mathbb{E}\left(x_{t}\right)$ & 0.000 & -0.003 & 0.000 & -0.002 & -0.001 & 0.000 \\
$\mathbb{V}\left(x_{t}\right)$ & 2.934 & 2.053 & 2.381 & 2.757 & 2.780 & 2.787 \\
$\mathbb{E}\left(\pi_{t}^{2}\right)+\lambda \mathbb{E}\left(x_{t}^{2}\right)$ & 1.020 & 1.248 & 1.096 & 0.973 & 0.887 & 0.946 \\
$\mathbb{P}\left(i_{t}=i^{L B}\right)$ & 0.000 & 0.273 & 0.205 & 0.202 & 0.076 & 0.088 \\
$\mathbb{E}\left(\pi_{t} \mid i_{t}=i^{L B}\right)$ & - & -1.389 & -1.124 & -0.701 & -0.650 & -0.650 \\
$\mathbb{E}\left(\pi_{t} \mid i_{t}>i^{L B}\right)$ & 0.000 & 0.185 & 0.290 & 0.178 & 0.056 & 0.154 \\
$\mathbb{E}\left(x_{t} \mid i_{t}=i^{L B}\right)$ & - & 1.567 & 1.875 & 2.225 & 2.561 & 2.503 \\
$\mathbb{E}\left(x_{t} \mid i_{t}>i^{L B}\right)$ & -0.000 & -0.591 & -0.484 & -0.566 & -0.213 & -0.242 \\
\hline$\theta_{0}$ & 1.000 & 1.000 & 0.900 & 1.000 & 1.000 & 1.000 \\
$\theta_{\mu}$ & 0.719 & 0.719 & 0.719 & 0.719 & 0.719 & 0.719 \\
$\theta_{E}$ & 1.722 & 1.722 & 1.722 & 1.722 & 1.722 & 1.722 \\
$\theta_{p}, \theta_{z}$ & 0.000 & 0.000 & 0.000 & 1.000 & 0.360 & 0.280 \\
\hline
\end{tabular}

Table 1: Moments of the unconditional distribution under various policy rules. We use the benchmark calibration for each policy framework in the model with supply shocks. 


\begin{tabular}{l|rrrrrr} 
& $\begin{array}{c}\text { Discretion } \\
\text { (no lower bound) }\end{array}$ & Discretion & $\begin{array}{c}\text { SAIT } \\
(E \pi=0)\end{array}$ & RW & PLT & TPLT \\
\hline \hline $\mathbb{E}\left(\pi_{t}\right)$ & 0.000 & -0.266 & 0.000 & -0.001 & 0.000 & -0.017 \\
$\mathbb{V}\left(\pi_{t}\right)$ & 0.000 & 0.137 & 0.060 & 0.009 & 0.007 & 0.007 \\
$\mathbb{E}\left(x_{t}\right)$ & 0.000 & -0.003 & 0.000 & 0.000 & 0.001 & -0.002 \\
$\mathbb{V}\left(x_{t}\right)$ & 0.000 & 0.215 & 0.093 & 0.019 & 0.029 & 0.027 \\
$\mathbb{E}\left(\pi_{t}^{2}\right)+\lambda \mathbb{E}\left(x_{t}^{2}\right)$ & 0.000 & 0.262 & 0.083 & 0.014 & 0.014 & 0.014 \\
$\mathbb{P}\left(i_{t}=i^{L B}\right)$ & 0.000 & 0.283 & 0.209 & 0.207 & 0.206 & 0.196 \\
$\mathbb{E}\left(\pi_{t} \mid i_{t}=i^{L B}\right)$ & - & -0.753 & -0.397 & 0.037 & -0.086 & -0.063 \\
$\mathbb{E}\left(\pi_{t} \mid i_{t}>i^{L B}\right)$ & 0.000 & -0.074 & 0.105 & -0.010 & 0.023 & -0.006 \\
$\mathbb{E}\left(x_{t} \mid i_{t}=i^{L B}\right)$ & - & -0.612 & -0.497 & -0.139 & -0.233 & -0.223 \\
$\mathbb{E}\left(x_{t} \mid i_{t}>i^{L B}\right)$ & 0.000 & 0.237 & 0.132 & 0.037 & 0.062 & 0.052 \\
\hline$\theta_{0}$ & 1.000 & 1.000 & 0.895 & 1.000 & 1.000 & 1.000 \\
$\theta_{\eta}$ & 0.800 & 0.800 & 0.800 & 0.800 & 0.800 & 0.800 \\
$\theta_{E}$ & 1.722 & 1.722 & 1.722 & 1.722 & 1.722 & 1.722 \\
$\theta_{p}, \theta_{z}$ & 0.000 & 0.000 & 0.000 & 1.000 & 1.500 & 2.290 \\
\hline
\end{tabular}

Table 2: Moments of the unconditional distribution under various policy rules. We use the benchmark calibration for each policy framework in the model with demand shocks. 